\title{
Near Infrared Spectroscopic Calibration Models For Real Time Monitoring Of Powder Density
}

Andrés D. Román-Ospino ${ }^{\mathrm{a}}$, Ravendra Singh $^{\mathrm{b}}$, Marianthi Ierapetritou ${ }^{\mathrm{b}}$, Rohit Ramachandran ${ }^{\mathrm{b}}$, Rafael Méndez ${ }^{c}$, Carlos Ortega-Zuñiga ${ }^{\text {a }}$, Fernando J. Muzzio ${ }^{b}$, Rodolfo J. Romañach ${ }^{\mathrm{a}}$

a Engineering Research Center for Structured Organic Particulate Systems (C-SOPS), Department of Chemistry, University of Puerto Rico, Mayaguez Campus, Mayaguez, PR 00681, USA

b Engineering Research Center for Structured Organic Particulate Systems (C-SOPS), Department of Chemical and Biochemical Engineering, Rutgers, The State University of New Jersey, Piscataway, NJ 08854, USA

${ }^{c}$ Engineering Research Center for Structured Organic Particulate Systems (C-SOPS), Department of Chemical Engineering, University of Puerto Rico, Mayaguez Campus, Mayaguez, PR 00681, USA

\section{Abstract}

Near infrared spectroscopic (NIRS) calibration models for real time prediction of powder density (tap, bulk and consolidated) were developed for a pharmaceutical formulation. Powder density is a critical property in the manufacturing of solid oral dosages, related to critical quality attributes such as tablet mass, hardness and dissolution. The establishment of calibration techniques for powder density is highly desired towards the development of control strategies. Three techniques were evaluated to obtain the required variation in powder density for calibration sets: 1) different tap density levels (for a single component), 2) generating different strain levels in powders blends (and as consequence powder density), through a modified shear Couette Cell, and 3) applying normal forces during a compressibility test with a powder rheometer to a pharmaceutical blend. For each variation in powder density, near infrared spectra were acquired to develop partial least squares (PLS) calibration models. Test samples were predicted with a relative standard error of prediction of $0.38 \%, 7.65 \%$ and $0.93 \%$ for tap density (single component), shear and rheometer respectively. Spectra obtained in real time in a continuous manufacturing $(\mathrm{CM})$ plant were compared to the spectra from the three approaches used to vary powder density. The calibration based on the application of different strain levels showed the greatest similarity with the blends produced in the CM plant. 
Keywords: Near Infrared Spectroscopy (NIRS), Powder rheometer, Powder density, Monitoring, Process Analytical Technology (PAT), and Quality by Design (QbD). 


\section{Introduction}

Powder density variation during tablet manufacturing produces variability in tablet mass, hardness and dissolution. Variation in tablet mass leads to incorrect amounts of drug delivered to patients. The challenges of controlling tablet mass have been barely addressed (Singh et al., 2015), even though many studies have addressed the control of blend uniformity to deliver the drug amount specified in label claims to patients (Colón et al., 2014; Esbensen et al., 2016; Igne et al., 2011; Mateo-Ortiz et al., 2014; Romañach, 2015; Rosas et al., 2012; Sekulic et al., 1996; Ufret and Morris, 2001; Vanarase et al., 2010). This report describes the development of a method to determine powder density based on near infrared (NIR) spectra obtained in real time.

Powder density measurements could provide important information in synergy with the process analytical technology (PAT) initiative (FDA, 2004). PAT strategies often involve near infrared spectroscopy for in-line prediction of blend uniformity at stages before the tablet press (Blanco et al., 2011; Corredor et al., 2015; Liew et al., 2010; Vanarase et al., 2010) and also at the feed frame (Mateo-Ortiz et al., 2014). However, even when blend uniformity is adequate, if density changes during the process, undesirable variation in tablet weight will occur and tablets will be produced with an excess or lack of the active pharmaceutical ingredient (API). Thus, PAT systems must address the control of drug concentration and powder density.

A closed loop control strategy was developed for pharmaceutical tablets manufacturing with NIR as PAT tool focused on API concentration (Singh et al., 2013; Singh et al., 2014). Principal component analysis was used as a supervisory technique coupled with the control system. NIR predictions were considered acceptable if projection of production samples are spatially consistent (Mahalanobis distance) with blend standards. This qualitative inspection in real time allowed appropriate quantitative measurements by a partial least squares calibration model. The 
control strategy was applied in continuous manufacturing where feeders must dispense each raw material at a specific ratio (Singh et al., 2014). The continuous blender provides the dynamics required to mix the raw materials then tablets are obtained after the compaction step. Thus, a fast response is required the real-time sensors for PAT to be achieved.

The first challenge for a PAT method is that the definition of powder density depends on the circumstances of measurement (Hancock et al., 2003). Powder density may be measured without shaking, vibration, tapping or normal forces applied (Abdullah and Geldart, 1999), and the term aerated powder density is used. Tapped bulk density refers to the operation of forcing a rearrangement of particles through tapping removing air partially from the powder (Hancock et al., 2003). This technique is included in U.S pharmacopeia section 616 for tapped bulk density in powders (Pharmacopeia, 2014). The term true density is used for determinations using a gas pycnometer. True density in related only to the material without porosity (Cao et al., 2008). This type of analysis provides accurate values for density but can only be performed off-line, and real time information cannot be delivered. The development of a real time method for powder density is also challenging because of the handling particulate materials and segregation that may occur because blends consist of aggregates of different particle size (Hastie, 2015).

In addition to the intrinsic properties of materials, processing effects such as normal forces at different levels of feeders, shear during blending and particle size distribution produces changes in powder density properties (Frake et al., 1998; Freeman, 2007; Fu et al., 2012; Jallo et al., 2012). These process induced effects make it difficult to obtain the required variation to construct calibration models for in-line prediction by near infrared spectroscopy.

Different off-line measurements have been performed for powder bulk density characterization in powder beds as by X-ray micro-computerized tomography. Density changes 
were monitored during mechanical shaking, and higher variation was observed for less cohesive powders (Mendez et al., 2011). The effect of particle size and bulk density was also evaluated in die fill of powder where it was found that a larger particle size flowability profile allowed more efficient die filling due to low cohesivity. Better flowability properties were found for low bulk density powders (Mills and Sinka, 2013). Bulk density has been successfully monitored constructing the calibration set through the extraction of actual manufacturing granules. PCA was used to project production samples and qualitatively ensure similarities with the calibration set. Partial Least Squares regression was used for quantitative analysis for samples properly projected in the calibration set of PCA (Alcalà et al., 2010). In-Situ monitoring of bulk density was achieved by using a microwave resonance sensor in the $600-750 \mathrm{MHz}$ region. This approach was implemented for powder samples of microcrystalline cellulose and the water content was also estimated simultaneously (Austin and Harris., 2014).

Flowability properties in powders were related to baseline changes in near infrared diffuse reflectance spectra (Beach et al., 2010; Ropero et al., 2009). Near infrared spectra were acquired during powder voiding and the amount of powder in front of the instrument was performed by measuring the radiation returning to the detector. Lower baseline and good signal to noise ratio was obtained for powders with good flowability. When the amount of powder voiding decreases due to lack of flowability, a high baseline was obtained with poor signal to noise ratio (Ropero et al., 2009).

This report describes the construction and implementation of a method for real time prediction of powder density. This PAT tool is able to differentiate powder density from other process variables such as API concentration. Powder bulk density calibration models described in this work contribute to process control providing information in real time to minimize the 
variability in tablet weight, hardness and thereby tablet dissolution. For this application, an extensive validation was performed across the entire calibration sets. The three approaches represent different scenarios where powder density changes can occur. The study also contributes to the fundamental understanding of the interaction between NIR radiation and particles (Barnes et al., 1989; Dahm, 2013; Frake et al., 1998) which is essential for the characterization of sources of variation as required by the Process Validation Guidance (U.S. Department of Health and Human Services, 2011).

\section{Materials and methods}

\subsection{Excipients, active pharmaceutical ingredient and blending}

Acetaminophen (APAP) USP/paracetamol ph Eur semi-fine powder and magnesium stearate NF non-bovine were obtained from Mallinckrodt Inc. (Raleigh NC and Saint Louis, MO, USA respectively). Microcrystalline cellulose (MCC) PH 101 was obtained from FMC BioPolymer (Newark, DE, USA), and used as the principal excipient and magnesium stearate (MgSt) as lubricant. Silicified microcrystalline cellulose (SMCC) HD 90 from JRS pharma (Rosenberg, Germany) was selected for initial experiments due to good flow properties and compactibility.

\subsection{Preparation of blends}

Batches of $500 \mathrm{~g}$ were prepared in a $400 \mathrm{ml} \mathrm{V}$-blender. A first layer of MCC was added to the V-blender, followed by the APAP, and then a second portion of MCC. These two materials 
were mixed at $30 \mathrm{rpm}$ (revolutions per minute) for $60 \mathrm{~min}$ and then $\mathrm{MgSt}$ was added and blended during four minutes. A rotary sample divider PT-100 from Retsch (Verder Scientific Inc.) was then used to divide the blend into eight portions (60 $\mathrm{g}$ each approximately).

A second set of blends were prepared to develop a NIR calibration model for APAP concentration in the range 10 to $20 \% \mathrm{w} / \mathrm{w}$ in steps of $2.5 \%(\mathrm{w} / \mathrm{w})$ using the $400 \mathrm{ml} \mathrm{V}$-blender. This model was constructed to evaluate the drug concentration prediction in samples subject to normal forces by using a powder rheometer as reference. These blends were prepared following the same blending protocol used for compressibility test (see section 2.5.3). Each blend was partitioned by using the sample divider into eight aliquots. Each aliquot was transferred to the rheometer vessel and subjected to the conditioning cycle. Normal forces were not applied and a NIR spectrum was acquired for each aliquot. A total of 40 calibration spectra were used for the API concentration calibration model.

\subsection{NIR spectral acquisition and repeatability study}

NIR spectra were obtained with a Matrix-F FT-NIR spectrometer from Bruker Optics (Billerica, MA, USA). A total of 32 scans were obtained per sample and averaged. The acquisition time for this setting including processing is approximately $6.0 \mathrm{~s}$. The background spectra were obtained with a total of 64 averaged scans. All near infrared spectra were obtained with a resolution of $16 \mathrm{~cm}^{-1}$ and the Opus 7.2 software. The Control Process feature from the Opus software was used for continuous spectral acquisition. 
A repeatability study was performed for each approach to estimate short term precision. Six consecutive spectra were obtained without moving the sample and the standard deviation was calculated as an estimation of the repeatability for each method.

\subsection{Multivariate analysis}

SIMCA Version 14 (MKS Data Analytics Solutions Umeå, Sweden) was used for construction of calibration models in four different spectral ranges. Data pretreatments such as the Standard Normal Variate (SNV) transformation, first and second derivative were performed in the selected spectral range previous to PLS fitting with mean centering as scaling. Combinations of SNV and derivatives were also performed applying SNV in the selected range and then derivatives. All derivatives were calculated by Savitzky-Golay algorithm with a 25point segment size and a second-order polynomial. The calibration models were evaluated by the prediction of independent samples by the calculation of:

$$
\begin{array}{ll}
\text { RMSEP }=\sqrt{\frac{\sum_{\mathrm{i}=1}^{\mathrm{n}}\left(\hat{\mathrm{y}}_{\mathrm{i}}-\mathrm{y}_{\mathrm{i}}\right)^{2}}{\mathrm{n}}} & \text { Equation 1. } \\
\operatorname{RSEP}=\sqrt{\frac{\sum_{\mathrm{i}=1}^{\mathrm{m}}\left(\hat{\mathrm{y}}_{\mathrm{i}}-\mathrm{y}_{\mathrm{i}}\right)^{2}}{\sum_{\mathrm{i}=1}^{\mathrm{m}} \mathrm{y}_{\mathrm{i}}^{2}}} * 100 \% & \text { Equation 2 }
\end{array}
$$

Root Mean Square Error of Prediction (RMSEP) is used for evaluation of calibration models (Equation 1). Due to low magnitude of tap, bulk and compressed powder density values, the relative standard error of prediction (RSEP \%) (Equation 2) was used to evaluate calibration 
models (Blanco et al., 2008). The RSEP (\%) normalizes the square of residuals by the square of reference values, providing a parameter independent of the magnitude.

The Unscrambler X (CAMO Oslo, Norway) and Process Pulse were used for real time prediction in continuous blending experiments.

\subsection{Tap, shear and compressed powder density}

Three different types of calibration sets were developed to address the effect on powder density of three possible process induced changes.

2.5.1. Tap density: A $500 \mathrm{ml}$ glass graduated cylinder was partially filled with silicified microcrystalline cellulose (SMCC) and mounted on top of a tap density instrument (VanKel Tap Density Tester Model 50 1200). NIR spectra were acquired by placing the FT-NIR spectrometer perpendicular to the graduated cylinder and obtaining spectra through the glass of the cylinder. The powder was released into the cylinder without shaking, the initial volume was measured and near infrared spectra were acquired (0 taps in Table 1). Four additional volumes were achieved decreasing according the number of taps, each volume change corresponding to $-10.0 \mathrm{ml}$. The tap density approach was only performed for the SMCC and was not used for blends to avoid segregation. Tap density was performed to investigate its effect on NIR spectra.

2.5.2. Shear cell: A modified shear Couette cell, consisting of two concentrically positioned cylinders, was used to apply strain to blends. Powders were placed between the concentric cylinders while the internal cylinder rotated. This system is not shown as photographs of the system have appeared in previous publications (Hernández et al., 2016; Llusa et al., 2009; Mehrotra et al., 2007). Each cylinder contains a certain number of blades controlling revolutions 
per minute (rpm). The shear cell was used at $80 \mathrm{rpm}$ and different strain levels were set by adjusting the time within the Couette cell. Blends with strain levels of 0, 80, 160, 240, 320, 480, 600,800 revolutions were prepared. The bulk density of the blends was measured by pouring blends (overfilling) into a cylindrical container of $180 \mathrm{~cm}^{3}$ that includes a bottom window transparent to NIR radiation. The surface of blend was flattened with a metal ruler without applying force on the powder column to obtain a similar volume for each measurement. An attachment was placed to NIR instrument emission head which allows spectral acquisition at the correct focusing distance. The samples with the cylindrical container was placed on top of this attachment.

2.5.3. FT4 powder Rheometer: The compressibility test from an FT4 powder rheometer (Freeman Technology Ltd., Worcestershire, UK,) was used to apply normal forces to a column of powder producing different levels of consolidated density. The piston is designed to apply normal forces allowing entrapped air to escape while the powder is compressed. The operational program includes a conditioning cycle with a blade at low revolutions contributing to reproducibility of consolidated bulk density. The glass cylinder shown in Fig 1 (step 3) consists of two sections one above the other, the upper section was separated to discard the excess of powder as shown in step 4 . NIR radiation was focused at $9.0 \mathrm{~cm}$ on the lower section of the vessel.

Figure 1. Experimental setup for powder rheometer approach. The Normal stress applied was between $0.1-4.0 \mathrm{kPa}$. 


\subsection{Continuous manufacturing pilot plant}

In the pilot plant experiments a loss-in-weight feeder from (Schenck) was filled with SMCC. A co-mill from Glatt was used for delumping. A convective continuous blender (Gericke) was used followed by a cylindrical chute with the interface for the Matrix FT-NIR spectrometer. The total inlet flow rate, for the entire configuration was $20 \mathrm{lb} / \mathrm{h}$ (pound per hour). Tap density which implies a single component was tested by one feeder configuration, while in the other two approaches (shear and powder rheometer) blends were used and two feeders.

\section{Results and discussion}

\subsection{Spectral response to density changes in calibration sets}

\subsubsection{Changes in NIR spectra after tapping}

Table 1 shows tap density values calculated from mass and each change in volume. The number of taps was intended to produce a decrease in volume of approximately $10.0 \mathrm{ml}$. An initial set of spectra were acquired after the powder was deposited in the graduated cylinder and then up to 500 taps were applied. Figure 2 (top) shows NIR spectra from $7350-7190 \mathrm{~cm}^{-1}$ and the baseline changes that occur as the number of taps is increased while the NIR spectra are obtained. As tap density increases, the spectral baseline increased for the first four calibration spectra, but the fifth value (500 taps) displayed a lower baseline. This reversal in the direction of the baseline changes could be due to percolation of particles. The first derivative eliminated the 
differences in baseline, but some spectral differences still remained after the first derivative was applied (Fig. 2-bottom). The experiment was conducted three times with similar results.

The baseline differences observed in calibration spectra depend on the fraction of radiation remitted to the detector (1/c) (Næs et al., 2002; Romañach et al., 2014; Ropero et al., 2009). The baseline changes can be described by the following equations:

$$
\begin{array}{cc}
I_{\text {det }}=\left(\frac{1}{c}\right) I_{\text {refl }} & \text { Equation } 3 \\
A_{\text {detected }}=-\log \left(R_{\text {detected }}\right)=-\log \left(\frac{I_{\text {det }}}{I_{0}}\right) & \text { Equation } 4 \\
A_{\text {detected }}=-\log \left(\frac{1}{c}\right)\left(\frac{I_{\text {refl }}}{I_{0}}\right)=\log c+A & \text { Equation } 5
\end{array}
$$

Where $I_{o}$ is the background spectrum, $I_{\text {det }}$ is the detected radiation which depends on the fraction $(1 / \mathrm{c})$ of the diffuse reflected radiation $\left(\mathrm{I}_{\text {refl }}\right)$ that reaches the detector. $\mathrm{I}_{\mathrm{refl}}$ and $1 / \mathrm{c}$ will change after each set of taps is applied and the packing of the particles is altered. These terms are then substituted into the Absorbance $=-\log \mathrm{R}$ equation that is used in NIR spectroscopy. The spectra obtained for the same material will differ in baseline by $\log \mathrm{c}$ as shown in equation 5 . 
Table 1. Tap density values obtained for each change in volume. Each tap density value was used as reference values for PLS calibration model.

Figure 2. Variation in calibration spectra for tap density measurements. Top- NIR spectra, bottom- $1^{\text {st }}$ derivative of NIR calibration spectra.

\subsubsection{Spectral changes after applying strain}

The bulk density was varied by applying different levels of strain to $15 \%$ w/w APAP blends with the Couette cell. This experiment only presents bulk density results since tapping was not performed. The strain reduced possible APAP agglomerates and increased the lubricant distribution, increasing the powder density. The baseline of the NIR spectra increased as the level of strain was increased. The higher density facilitated transmission of the radiation, and less radiation reached the diffuse reflectance detector and the baseline increased. The reversal in the direction of the baseline changes, which occurred in the tap density experiments, was not observed in this case. Figure 3 (top) shows the NIR spectra acquired. The first derivative eliminated the differences in baseline, but subtle spectral differences were still observed (Fig. 3 bottom). The first derivative spectra varied according to the strain applied.

Figure 3. Variation in calibration spectra after applying strain with the Couette cell. a) NIR spectra, b) $1^{\text {st }}$ derivative of NIR calibration spectra. 
3.1.3. Changes in NIR spectra during compressibility test with powder rheometer.

Figure 4 shows the NIR diffuse reflectance spectra acquired during the compressibility test performed with the FT4 rheometer. The baseline increased as the powder density increased as in the previous experiments discussed in this study (Fig. 4 top). The increase in baseline is indicative of less radiation reaching the detector (Romañach, 2014; Ropero et al., 2009). Thus, the physical effects applied on powders are detected by near infrared spectroscopy. This result is consistent with previous studies where diffuse reflectance was evaluated in tablets under different levels of compression pressure even when the applied force in this study is three magnitude orders lower (Otsuka et al., 2007; Short et al., 2009). The studies showed that transmission of NIR radiation is favored with higher compression forces. This experiment, under controlled conditions, confirms that consolidation of the powder results in less diffusely reflected radiation as the transmitted radiation increases.

Figure 4 also shows the first derivative spectra. This data pretreatment removed the baseline and significantly reduced spectral differences. However, slope differences still exist in the spectra after the first derivative is performed (Fig. 4 bottom). A second order polynomial relationship between powder density and spectral slope was observed and is discussed in section 3.4 .

Figure 4. Variation in calibration spectra after powder consolidation performed with FT4 rheometer. Top - NIR spectra, bottom- $1^{\text {st }}$ derivative of NIR calibration spectra. 


\subsection{Partial Least Squares calibration models}

Four spectral regions were selected for calibration models based on the three approaches followed to vary powder density (tap density, variation of strain, and compressibility). Since powder density is a physical property, wide spectral ranges were considered. The 11900-4100 $\mathrm{cm}^{-1}$ range included most of the NIR spectrum only avoiding high noise areas. The 9000-4100 $\mathrm{cm}^{-1}$ excludes regions with low absorbance values where the radiation penetrates more (12000 $9000 \mathrm{~cm}^{-1}$ ). The $11900-5550 \mathrm{~cm}^{-1}$ range omits the stronger absorbance areas where the radiation penetrates less and also the $\mathrm{O}-\mathrm{H}$ combination band. The $7500-5000 \mathrm{~cm}^{-1}$ range includes the first $\mathrm{C}-\mathrm{H}$ overtone bands, and the $\mathrm{O}-\mathrm{H}$ first overtone and combination band.

\subsubsection{Tap density approach}

A first set of NIR spectra were obtained after $290.5 \mathrm{~g}$ of SMCC was deposited in the $500 \mathrm{~mL}$ graduated cylinder and then tapping was performed up to 500 taps as described in Table 1 . NIR spectra were acquired for calibration after each $10 \mathrm{ml}$ of volume change. PLS calibration models were constructed by using four spectral ranges, five pretreatments and without pretreatment (24 calibration models each). The $\mathbf{Y}$ values were the tap density values shown in Table 1. Two tap experiments were performed as an independent validation set. Both evaluations were performed across the entire calibration set. Since actual manufacturing conditions implies blends, this approach was performed as a proof of concept to evaluate the NIR response to changes in tap density. All calibration models evaluations were performed across the entire prediction set comprising the same amount of prediction samples as the calibration set. 
Table 2 shows evaluation of calibration models based on independent samples. Calibration models were developed with and without data pretreatments. Five data pretreatments were explored for the models that includes data pretreatments. Models without data pretreatment maintained the entire NIR spectral variation, while the Standard Normal Variate (SNV) removed multiplicative and additive scattering effects and their effects in powder density determination were evaluated. The derivative removed baseline offsets. Baseline and slope are related with physical properties of powder samples as shown in equations 3-5 and are subject of evaluation in calibration models for spectroscopic powder density determination. Finally a combination of these data pretreatments (SNV+derivatives) was also evaluated.

PLS calibration models were constructed under these parameters over four spectral ranges selected as described in section 3.2. Table 2 shows PLS calibration models predicting independent experiments and the RSEP (\%) was calculated for each calibration model. The calibration model based on the first derivative in the spectral range $7500-5000 \mathrm{~cm}^{-1}$ predicted test set samples with the lowest error of prediction $(\mathrm{RSEP}=0.38 \%)$ using 2 PLS factors, and with a repeatability (precision) of $0.001 \mathrm{~g} / \mathrm{cm}^{3}$. Figure 5 (top) shows PLS scores of this calibration model representing the change in tap density as the first principal component which accounts for 95.6\% of the variance explained the model. The model with 2 PLS factors was selected for prediction since it encompassed $98.4 \%$ of the variance explained by the model. Figure 5 (bottom) shows PLS scores projection of the independent set into the calibration model represented in Fig. 5 (top). Thus, the calibration encompassed the variation observed in the independent set of experiments. 
Figure 5. PLS scores of calibration model based on tap density approach. Scores based on $1^{\text {st }}$ derivative from $7450-7075 \mathrm{~cm}^{-1}$. Progression of the first component is shown from left to right: white hexagons: $0.493 \mathrm{~g} / \mathrm{cm}^{3}$, black hexagons: $0.501 \mathrm{~g} / \mathrm{cm}^{3}$, white diamonds: $0.510 \mathrm{~g} / \mathrm{cm}^{3}$, black triangles: $0.519 \mathrm{~g} / \mathrm{cm}^{3}$ and white squares: $0.528 \mathrm{~g} / \mathrm{cm}^{3}$. Bottom PLS score projection of independent set for the tap density with similar progression in tap density as the calibration set.

Table 2. Evaluation of calibration models for tap density approach in four different spectral ranges.

\subsubsection{Prediction of powder bulk density changes induced by Couette cell}

Eight calibration blends consisting in $15 \% \mathrm{w} / \mathrm{w}$ APAP, $84 \% \mathrm{w} / \mathrm{w}$ SMCC and 1\% w/w were prepared in a v-blender $(1 \mathrm{~kg}$ each). Each blend was divided into three portions $(\approx 300 \mathrm{~g})$ and transferred to the shear Couette cell where strain was varied by applying up to 800 revolutions. Higher levels of strain were achieved by increasing the time inside the Couette cell. After applying shear, blends were transferred overfilling a cylindrical NIR interface and normalizing the surface to obtain constant volume $(180 \mathrm{ml})$. The bulk density was directly proportional to the increase in revolutions from 0 to 240 as shown in Fig. 6 . The bulk density values obtained from 0 to 240 revolutions were used as reference values for the PLS calibration model; since the density did not increase beyond the strain applied with 240 revolutions. 
Figure 6. Powder bulk density values for different shear levels. Three samples were evaluated for each shear level labeled as $\rho 1$ (circle), $\rho 2$ (diamond) and $\rho 3$ (triangle).

Table 3 shows the quantitative evaluation of calibration models by an independent experiment constructed in four spectral ranges and with five data pretreatment methods. The lowest RSEP (\%) values correspond to the calibration model with second derivative as data pretreatment from $7500-5000 \mathrm{~cm}^{-1}$ by using 1-PLS factor, however this calibration model only includes $35.4 \%$ of the spectral variation. The calibration model with the first derivative includes $81.4 \%$, and predicts the test set with an RSEP $=7.65 \%$ with 1-PLS factor and was selected for continuous blending experiments. The standard deviation for the repeatability studies for shear was $0.003 \mathrm{~g} / \mathrm{cm}^{3}$. The PLS scores plot of $1^{\text {st }}$ derivative calibration model is depicted in Fig. 7. The variation in powder bulk density represents the first component. Figure 7 shows the projection of independent replicate experiments into the PLS scores plot; the model encompasses the variation observed in the independent samples. The strain applied by the Couette cell reduces the API agglomerates, increases lubricant distribution and then higher amounts of blend can be packed inside the cylindrical NIR interface.

Figure 7. Top: PLS scores of calibration samples based on shear Couette Cell approach. Scores based on 1st derivative from 7500-5000 $\mathrm{cm}^{-1}$. Bottom: PLS score projection of independent set in the shear Couette Cell approach calibration model. Only independent samples were projected in with similar progression in bulk density as the calibration set. From left to right: white hexagons, $0.500 \mathrm{~g} / \mathrm{cm}^{3}, 0$ revs; black hexagons, $0.543 \mathrm{~g} / \mathrm{cm}^{3}, 80$ revs ; diamonds, $0.559 \mathrm{~g} / \mathrm{cm}^{3}$, 160 revs; triangles, $0.581 \mathrm{~g} / \mathrm{cm}^{3}, 240$ revs. 
Table 3. Evaluation of calibration models for shear Couette cell approach in four different spectral ranges and four data pretreatment

\subsection{Calibration model for powder density by consolidation with FT4 powder rheometer}

Figure 8 (top) shows the compressibility test program used (kPa values) with the powder rheometer to develop the calibration models, and compressed powder density values. The piston height was programmed to remain constant during $100 \mathrm{~s}$ for NIR spectral acquisition at each predetermined change in powder density. Reference values were obtained from the compressibility test and paired with the corresponding NIR spectrum to build partial least squares calibration models. Each run (compressibility test program) provided ten powder density levels and for each run calibration models were developed with four spectral ranges, five pretreatments and without pretreatment (24 calibration models each). Six replicate runs were used to develop and test the calibration models. The calibration models developed from one run were used to predict powder density in the other runs. For example when experiment \#1 was used as calibration, the other five runs were used as a prediction set. Table 4 shows the prediction of run \#4 with the calibration model developed with run \#1. The model was developed with the spectral range 7500-5000 $\mathrm{cm}^{-1}$ with first derivative and using two PLS factors which provided the lowest prediction error $(\operatorname{RSEP}=0.93 \%)$, and the standard deviation for the repeatability studies was $0.003 \mathrm{~g} / \mathrm{cm}^{3}$.

Even under the highly controlled experimental circumstances at the powder rheometer the baseline observed was not always the same because of variation in the initial state of powder 
density in the area analyzed by the NIR spectrometer. Slight baseline differences between experiments led to over or under prediction, making models based only on baseline changes not suitable for validation. The use of the standard normal variate (SNV) transformation reduced the prediction error only in cases where the initial state (baseline) of calibration set was similar to the prediction set. The use of SNV with first derivative or second derivative increased the noise and discrimination between compressed powder density levels was difficult.

Table 4. Evaluation of calibration models for FT4 approach. PLS calibration model based on run $\# 1$ and run \#4 as prediction set.

Figure 8 (top) shows the compressibility test program from the FT4 powder rheometer. NIR spectra were acquired during each stage and paired with the compressed powder density value for PLS models. Figure 8 (middle) shows PLS scores for the calibration model with the lowest RSEP $(\%)\left(1^{\text {st }}\right.$ derivative, 2 PLS factors in the spectral range $\left.7500-5000 \mathrm{~cm}^{-1}\right)$. The first principal component from left to right depicts the increment in powder density. The nine compression stages can be easily identified with their respective scores from 1-9 (Fig. 8). The white hexagons represent the NIR spectra acquired for the consolidated bulk density (CBD) this corresponds to the powder density value immediately after the conditioning process and before the application of normal force) and the black circles characterize the highest powder density value. Figure 8 (bottom) shows the projection of an independent experiment into the PLS scores plot from the calibration set. The changes in compressed powder density are shown along the first principal component obtained for this independent experiment. 
Figure 8. Top: Compressibility test program at the FT4 powder rheometer. NIR spectra were acquired during each stage and paired with the compressed powder density value for PLS models. Middle: PLS scores projection of powder density calibration model by rheometer approach. Bottom: PLS score projection of an independent set in powder rheometer calibration model.

Table 4 shows that the $1^{\text {st }}$ derivative in the spectral range $7500-5000 \mathrm{~cm}^{-1}$ and 2-PLS factors produced the lowest error of prediction of an independent experiment. When a run was used for calibration, the other five were used as independent validation for a total of 30 evaluations. For each assessment, the RSEP (\%) value was calculated. Since each prediction set comprises the entire compressibility test, all RSEP (\%) values include the error of prediction of 10 density levels. Table 5 shows the RSEP (\%) for the 30 evaluations.

Table 5. RSEP (\%) values obtained for 30 evaluations from 6 experiments used as calibration or prediction set. All RSEP (\%) values were calculated across the entire prediction set with 10 different compressed powder density levels.

The success of the calibration model with the first derivative pretreatment indicates the importance of the spectral slope. The first derivative eliminates baseline variation while the spectral slope remains. Slopes were calculated by the first and last data points in the $7500-5000$ $\mathrm{cm}^{-1}$ spectral range. Figure 9 shows the plot of slope vs powder density value, for this second order polynomial relationship ( $y=a^{2}+b x+c$, where $y$ is powder density), coefficients $a, b$ and $c$ were obtained for each experiment. The authors understand that this is the first study where the 
effect of powder compressibility on the NIR spectral slope has been studied under well controlled conditions. This experiment contributes to the fundamental understanding of NIR spectroscopy, which is important due to the increasing number of NIR procedures within PAT systems in the pharmaceutical industry (Alcalà et al., 2012; Simon et al., 2015).

Measurements of powder density values from the spectral slopes were performed by using the second order polynomial equation obtained from a calibration run and slopes from other five experiments were used as $\mathrm{x}$ value. Table 6 shows the thirty validations performed where an RSEP (\%) value under $7 \%$ was obtained. This is considered very good accuracy for measurements of powder density based on the spectral slope. These experiments suggest the use of first derivative as a reproducible manner to predict external samples for powder density. The good results with the spectral slope relationship recommend this approach as an alternative to PLS regression.

Figure 9. Second order polynomial based on spectral slopes calculated from $7500-5000 \mathrm{~cm}^{-1}$ and the respective powder density value.

Table 6. Evaluation of six experiments performed at powder rheometer with slopes calculated by two data points in the range $7500-5000 \mathrm{~cm}^{-1}$. Equations were obtained by second order polynomial fit and slopes from other five experiments were used as $\mathrm{x}$ value.

Partial least squares calibration models for API concentration were constructed to evaluate the effect of changes in consolidated powder density on the prediction of drug concentration. These experiments were conducted to determine whether drug concentration could be 
determined in spite of the powder density changes that occurred. These calibration models were evaluated by using eight independent blends subjected to the compressibility test. Twenty four calibration models for drug concentration were constructed in the same spectral ranges and pretreatments as powder density calibration models. The lowest error in the prediction of drug concentration was obtained in the $7500-5000 \mathrm{~cm}^{-1}$ spectral range with first derivative pretreatment and 3 PLS factors for an independent compressibility experiment. Figure 10 shows PLS predictions by using two and three PLS factors of the API concentration calibration model. The two PLS factor calibration model shows the increment in API concentration prediction that is affected by the powder density variation. The incorporation of a third factor explains the API concentration close to the target value of $15 \% \mathrm{w} / \mathrm{w},(14.97 \% \mathrm{w} / \mathrm{w}, \operatorname{RSEP}(\%)=1.09)$. This experiment supports the use of first derivative and two PLS factors for prediction of powder density. The experiment also shows that NIR spectroscopy may be used to monitor both drug concentration and powder density.

Figure 10. Drug concentration predicted by NIR calibration model for $15 \%$ w/w APAP blend during a compressibility test.

\subsection{Implementation of calibration models in a continuous manufacturing pilot plant}

Calibration models from the three approaches were used for real time prediction of continuous blending experiments. Spectral data acquisition was performed for a single component (one feeder configuration) to test the tap density approach and 15\% w/w APAP blends (two feeders configuration). 
3.5.1. Tap density approach: Figure 11 shows PCA scores projections of continuous blending experiments performed with SMCC in the tap density calibration set (first derivative in the spectral range $7500-5000 \mathrm{~cm}^{-1}$ - section 3.1). All spectra were projected within the $95 \%$ confidence interval of the calibration set, showing that variation obtained by the tap density approach was similar to the experiment of continuous blending by using a single component. Figure 11 (bottom) shows the quantitative analysis performed by PLS, with average value 0.506 $\mathrm{g} / \mathrm{cm}^{3}$, standard deviation of 0.002 and relative standard deviation of RSD $(\%)=0.48 \%$. The average powder bulk density value determined for SMCC is $0.501 \mathrm{~g} / \mathrm{cm}^{3}(\mathrm{n}=3)$.

Figure 11. Top - PCA scores projections of spectra from continuous manufacturing projected into score plot of tap density calibration model. Bottom - Continuous manufacturing predicted values for tap density approach calibration model.

3.5.2. Strain-based calibration model: Spectra from the continuous manufacturing process were projected into the scores plot of the PCA model developed from the spectra of samples where strain was varied (section 3.2.2). The calibration model based on first derivative in the spectral range $7500-5000 \mathrm{~cm}^{-1}$ produced projections of test samples within the first principal component (Fig. 12 top). The continuous manufacturing spectra are similar along the first principal component but not across the second principal component (Fig. 12 bottom). The differences in the PCA scores plot could be related to differences in how the spectra were acquired. The continuous blending spectra were acquired using a chute where the NIR spectrometer was attached perpendicular while the calibration samples were acquired with the spectrometer placed below. The two setups could result in differences in the consolidation of the powders and the differences observed in the PCA scores plot. The fluctuation in powder density was likely 
produced by the manual operation of chute valve. Figure 13 shows PLS predictions of powder density, average value obtained for this run was $0.554 \mathrm{~g} / \mathrm{cm}^{3}$, with a standard deviation of 0.02 and $\operatorname{RSD}(\%)=2.93 \%$.

Figure 12. PCA scores projections of spectra from continuous manufacturing projected into score plot of shear based calibration model. Top: 1-PC and bottom 2-PC.

Figure 13. Continuous manufacturing predicted values for shear approach calibration model.

3.5.3. Evaluation of calibration models developed with powder rheometer:

Figure 14 shows the projections of the scores from the continuous blending experiment. All samples were projected outside the PCA scores plot defined by the $1^{\text {st }}$ derivative of the calibration samples in the spectral range $7500-5000 \mathrm{~cm}^{-1}$, and similar results were obtained for the calibration models constructed with the other spectral areas and pretreatments. The NIR sensor position, immediately after the continuous blender is likely contributing to the differences observed between calibration set and spectra obtained from the continuous manufacturing experiment. The feeders, comil, and blender apply strain to powder (Singh et al., 2015), explaining the similarity along the first principal component in the shear approach. The powder rheometer approach, based on normal forces does not provide spectra similar to those observed in the continuous manufacturing experiment. However, the powder rheometer approach could be applied to prediction of powder density at feeders where density changes affects the flow rate during continuous manufacturing. 
Figure 14. PCA scores of spectra from continuous manufacturing projected into score plot of FT4 powder rheometer calibration model.

\section{Conclusions}

The three methods to induce stress on powders considered in this study allowed the development of standards with the variation required to build calibration models for prediction of powder density by near infrared spectroscopy.

The tap density approach focused on density changes produced by particle rearrangement and segregation, included variation from actual manufacturing condition as demonstrated in the implementation section. The shear-based methodology simulates the strain applied to powders during the continuous blending process such as feeders, continuous mixer, and paddles at the tablet press feed frame. The NIR sampling position allowed the successful implementation of tap density and shear approaches because at that section, both phenomena occur.

The powder rheometer strategy allowed higher control of the experiment, and enabled the understanding of density changes during compressibility due to normal forces. The relationship between slope and powder density observed in these experiments served as basis for the first

derivative data pretreatment at the other two approaches. Powder density variation obtained by normal forces at the FT4 powder rheometer was not reproduced in continuous blending experiment because other phenomena as shear and tap density are more representative. This type of calibration standards could be implemented in operation units where powders are subject to normal forces such as feeders (for feed-forward control strategies) and die filling a the tablet 
press (feed-back control). The powder rheometer experiment also showed that both powder density and drug concentration could be determined with NIR spectroscopy as the normal forces applied by the FT4 were varied.

The strategies followed in this study may be used to prepare standards with different levels of powder density for many pharmaceutical formulations. The experiments presented in this work contribute to the implementation of control strategies for critical properties such as tablet mass (API delivered to patient), hardness and dissolution.

\section{Acknowledgements}

This work is supported by the National Science Foundation Engineering Research Center on Structured Organic Particulate Systems, through Grant NSF-ECC 0540855.

\section{References}

Abdullah, E.C., Geldart, D., 1999. The use of bulk density measurements as flowability indicators. Powder Technology 102, 151-165.

Alcalà, M., Blanco, M., Bautista, M., González, J.M., 2010. On-line monitoring of a granulation process by NIR spectroscopy. J. Pharm. Sci. 99, 336-345.

Alcalà, M., Blanco, M., Menezes, J.C., Felizardo, P.M., Garrido, A., Pérez, D., Zamora, E., Pasquini, C., Romañach, R.J., 2012. Near-Infrared Spectroscopy in Laboratory and Process Analysis, Encyclopedia of Analytical Chemistry. John Wiley \& Sons, Ltd.

Barnes, R.J., Dhanoa, M.S., Lister, S.J., 1989. Standard Normal Variate Transformation and De-trending of Near-Infrared Diffuse Reflectance Spectra. Appl Spectrosc 43, 772-777.

Beach, L., Ropero, J., Mujumdar, A., Alcala, M., Romanach, R.J., Dave, R.N., 2010. Near-Infrared Spectroscopy for the In-Line Characterization of Powder Voiding Part II: Quantification of Enhanced Flow Properties of Surface Modified Active Pharmaceutical Ingredients. J Pharm Innov 5, 1-13.

Blanco, M., Bautista, M., Alcalà, M., 2008. API Determination by NIR Spectroscopy Across Pharmaceutical Production Process. AAPS PharmSciTech 9, 1130-1135. 
Blanco, M., Cueva-Mestanza, R., Peguero, A., 2011. NIR analysis of pharmaceutical samples without reference data: improving the calibration. Talanta 85, 2218-2225.

Cao, X., Leyva, N., Anderson, S.R., Hancock, B.C., 2008. Use of prediction methods to estimate true density of active pharmaceutical ingredients. Int J Pharm 355, 231-237.

Colón, Y., Florian, M., Acevedo, D., Méndez, R., Romañach, R., 2014. Near Infrared Method Development for a Continuous Manufacturing Blending Process. J Pharm Innov 9, 291-301.

Corredor, C., Lozano, R., Bu, X., McCann, R., Dougherty, J., Stevens, T., Both, D., Shah, P., 2015. Analytical Method Quality by Design for an On-Line Near-Infrared Method to Monitor Blend Potency and Uniformity. J Pharm Innov 10, 47-55.

Dahm, D.J., 2013. Review: Explaining some light scattering properties of milk using representative layer theory J. Near Infrared Spectrosc. 21, 322-339

Esbensen, K.H., Román-Ospino, A.D., Sanchez, A., Romañach, R.J., 2016. Adequacy and verifiability of pharmaceutical mixtures and dose units by variographic analysis (Theory of Sampling) - A call for a regulatory paradigm shift. Int J Pharm 499, 156-174.

FDA, 2004. Guidance for Industry PAT - A Framework for Innovative Pharmaceutical Development, Manufacturing, and Quality Assurance

Frake, P., Gill, I., Luscombe, C.N., Rudd, D.R., Waterhouse, J., Jayasooriya, U.A., 1998. Near-infrared mass median particle size determination of lactose monohydrate, evaluating several chemometric approaches. The Analyst 123, 2043-2046.

Freeman, R., 2007. Measuring the flow properties of consolidated, conditioned and aerated powders A comparative study using a powder rheometer and a rotational shear cell. Powder Technol. 174, 25-33. Fu, X., Huck, D., Makein, L., Armstrong, B., Willen, U., Freeman, T., 2012. Effect of particle shape and size on flow properties of lactose powders. Particuology 10, 203-208.

Hancock, B.C., Colvin, J.T., Mullarney, M.P., Zinchuk, A.V., 2003. The relative densities of pharmaceutical powders, blends, dry granulations, and immediate-release tablets. Pharm. Technol. 27, 64-80.

Hastie, D.B., 2015. On the difficulties of sampling bulk powder blends in determining segregation propensity - A case study. Powder Technol. 286, 164-171.

Hernández, E., Pawar, P., Rodriguez, S., Lysenko, S., Muzzio, F.J., Romañach, R.J., 2016. Effect of Shear Applied During a Pharmaceutical Process on Near Infrared Spectra. Appl Spectrosc 70, 455-466.

Igne, B., Zacour, B.M., Shi, Z.Q., Talwar, S., Anderson, C.A., Drennen, J.K., 2011. Online Monitoring of Pharmaceutical Materials Using Multiple NIR Sensors-Part I: Blend Homogeneity. J Pharm Innov 6, 47-59. Jallo, L.J., Ghoroi, C., Gurumurthy, L., Patel, U., Dave, R.N., 2012. Improvement of flow and bulk density of pharmaceutical powders using surface modification. Int J Pharm 423, 213-225.

Liew, C.V., Karande, A.D., Heng, P.W.S., 2010. In-line quantification of drug and excipients in cohesive powder blends by near infrared spectroscopy. Int. J. Pharm. 386, 138-148.

Llusa, M., Levin, M., Snee, R.D., Muzzio, F.J., 2009. Shear-induced APAP de-agglomeration. Drug development and industrial pharmacy 35, 1487-1495.

Mateo-Ortiz, D., Colon, Y., Romanach, R.J., Mendez, R., 2014. Analysis of powder phenomena inside a Fette 3090 feed frame using in-line NIR spectroscopy. J Pharm Biomed Anal 100, 40-49.

Mehrotra, A., Llusa, M., Faqih, A., Levin, M., Muzzio, F.J., 2007. Influence of shear intensity and total shear on properties of blends and tablets of lactose and cellulose lubricated with magnesium stearate. Int J Pharm 336, 284-291.

Mendez, R., Romanski, F.S., Tomassone, M.S., 2011. Density behavior of cohesive granular materials. Powder Technol. 211, 189-198. 
Mills, L.A., Sinka, I.C., 2013. Effect of particle size and density on the die fill of powders. Eur J Pharm Biopharm 84, 642-652.

Næs, T., Isaksson, T., Fearn, T., Davies, T., 2002. A User-Friendly Guide to Multivariate Calibration and Classification.

Otsuka, M., Tanabe, H., Osaki, K., Otsuka, K., Ozaki, Y., 2007. Chemoinformetrical evaluation of dissolution property of indomethacin tablets by near-infrared spectroscopy. J. Pharm. Sci. 96, 788-801.

Pharmacopeia, U.S., 2014. United States Pharmacopeia, USP 25-NF 20 (United States Pharmacopeial

Convention Inc., Rockville,MD, 2014).

Romañach, R.J., 2015. Sampling and Determination of Adequacy of Mixing, Pharmaceutical Blending and Mixing. John Wiley \& Sons, Ltd, pp. 57-78.

Romañach, R.J., Hernández Torres, E., Roman Ospino, A., Pastrana, I., Semidei, F., 2014. NIR and Raman Spectroscopic Measurements to Train the Next Generation of PAT Scientists. American Pharmaceutical Review 17, 82-87.

Romañach, R.J., Hernández Torres, E., Román-Ospino, A., Pastrana, I., Semidei, F., 2014. NIR and Raman Spectroscopic Measurements to Train the Next Generation of PAT Scientists. Am. Pharm. Rev. 17, 82-87.

Ropero, J., Beach, L., Alcalà, M., Rentas, R., Davé, R.N., Romañach, R.J., 2009. Near-infrared Spectroscopy for the In-line Characterization of Powder Voiding Part I: Development of the Methodology. J Pharm Innov 4, 187-197.

Rosas, J.G., Blanco, M., Gonzalez, J.M., Alcala, M., 2012. Real-time determination of critical quality attributes using near-infrared spectroscopy: a contribution for Process Analytical Technology (PAT). Talanta 97, 163-170.

Sekulic, S.S., Ward, H.W., Brannegan, D.R., Stanley, E.D., Evans, C.L., Sciavolino, S.T., Hailey, P.A., Aldridge, P.K., 1996. On-line monitoring of powder blend homogeneity by near-infrared spectroscopy. Anal Chem 68, 509-513.

Short, S.M., Cogdill, R.P., Wildfong, P.L.D., Drennen, J.K., Anderson, C.A., 2009. A Near-Infrared Spectroscopic Investigation of Relative Density and Crushing Strength in Four-Component Compacts. J. Pharm. Sci. 98, 1095-1109.

Simon, L.L., Pataki, H., Marosi, G., Meemken, F., Hungerbühler, K., Baiker, A., Tummala, S., Glennon, B., Kuentz, M., Steele, G., Kramer, H.J.M., Rydzak, J.W., Chen, Z., Morris, J., Kjell, F., Singh, R., Gani, R., Gernaey, K.V., Louhi-Kultanen, M., O’Reilly, J., Sandler, N., Antikainen, O., Yliruusi, J., Frohberg, P., Ulrich, J., Braatz, R.D., Leyssens, T., von Stosch, M., Oliveira, R., Tan, R.B.H., Wu, H., Khan, M., O'Grady, D., Pandey, A., Westra, R., Delle-Case, E., Pape, D., Angelosante, D., Maret, Y., Steiger, O., Lenner, M., Abbou-Oucherif, K., Nagy, Z.K., Litster, J.D., Kamaraju, V.K., Chiu, M.-S., 2015. Assessment of Recent Process Analytical Technology (PAT) Trends: A Multiauthor Review. Organic Process Research \& Development 19, 3-62.

Singh, R., lerapetritou, M., Ramachandran, R., 2013. System-wide hybrid MPC-PID control of a continuous pharmaceutical tablet manufacturing process via direct compaction. Eur. J. Pharm. Biopharm. 85, 1164-1182.

Singh, R., Román-Ospino, A.D., Romañach, R.J., lerapetritou, M., Ramachandran, R., 2015. Real time monitoring of powder blend bulk density for coupled feed-forward/feed-back control of a continuous direct compaction tablet manufacturing process. Int J Pharm 495, 612-625.

Singh, R., Sahay, A., Karry, K.M., Muzzio, F., lerapetritou, M., Ramachandran, R., 2014. Implementation of an advanced hybrid MPC-PID control system using PAT tools into a direct compaction continuous pharmaceutical tablet manufacturing pilot plant. Int J Pharm 473, 38-54.

U.S. Department of Health and Human Services, F.D.A., 2011. Guidance for Industry Process Validation: General Principles and Practices. Current Good Manufacturing Practices (CGMP), 1-22. 
Ufret, C., Morris, K., 2001. Modeling of powder blending using on-line near-infrared measurements. Drug development and industrial pharmacy 27, 719-729.

Vanarase, A.U., Alcalà, M., Jerez Rozo, J.I., Muzzio, F.J., Romañach, R.J., 2010. Real-time monitoring of drug concentration in a continuous powder mixing process using NIR spectroscopy. Chem. Eng. Sci. 65, 5728-5733. 


\begin{tabular}{|c|c|c|c|c|c|}
\hline Taps & 0 & 5 & 10 & 100 & 500 \\
\hline $\mathrm{v}\left(\mathrm{cm}^{3}\right)$ & 590.0 & 580.0 & 570.0 & 560.0 & 550.0 \\
\hline$\Delta \mathrm{v}(\%)$ & 0.00 & 1.69 & 3.39 & 5.08 & 6.78 \\
\hline$\rho\left(\mathrm{g} / \mathrm{cm}^{3}\right)$ & 0.493 & 0.501 & 0.510 & 0.519 & 0.528 \\
\hline
\end{tabular}




\begin{tabular}{|c|c|c|c|c|c|c|}
\hline & & & Spectral I & $\operatorname{ange}\left(\mathrm{cm}^{-1}\right)$ & & \\
\hline Data pretreatment $\downarrow$ & $\begin{array}{c}\text { Number } \\
\text { of PLS } \\
\text { Factors } \downarrow\end{array}$ & $11900-4100$ & $9000-4100$ & 11900-5550 & $7500-5000$ & \\
\hline & 1 & 1.93 & 1.90 & 2.01 & 1.91 & \\
\hline None & 2 & 3.51 & 4.30 & 2.71 & 3.38 & \\
\hline & 3 & 2.84 & 3.38 & 3.05 & 2.31 & \\
\hline & 4 & 2.77 & 3.10 & 2.72 & 2.62 & \\
\hline & 1 & 2.07 & 1.88 & 2.24 & 2.05 & \\
\hline SNV & 2 & 2.03 & 1.82 & 0.67 & 1.61 & \\
\hline & 3 & 0.47 & 1.41 & 0.47 & 1.00 & \\
\hline & 4 & 0.43 & 1.42 & 0.49 & 1.05 & \\
\hline & 1 & 1.85 & 1.85 & 1.69 & 1.74 & \\
\hline $\mathbf{1}^{\text {st }}$ derivative & 2 & 1.52 & 1.50 & 1.24 & 0.38 & \\
\hline & 3 & 1.10 & 1.03 & 0.96 & 0.30 & \\
\hline & 4 & 0.93 & 0.81 & 0.77 & 0.30 & \\
\hline & 1 & 1.69 & 1.66 & 1.84 & 0.50 & {$[-1]$} \\
\hline $2^{\text {nd }}$ derivative & 2 & 1.37 & 1.30 & 1.29 & 0.42 & (n \\
\hline & 3 & 1.03 & 0.90 & 0.99 & 0.43 & \\
\hline & 4 & 0.83 & 0.52 & 0.77 & 0.43 & \\
\hline & 1 & 1.69 & 1.55 & 1.30 & 0.95 & \\
\hline $\mathrm{SNV}+1^{\text {st }}$ derivative & 2 & 1.18 & 1.16 & 0.83 & 0.84 & \\
\hline & 3 & 0.78 & 0.77 & 0.66 & 0.94 & \\
\hline & 4 & 0.70 & 0.72 & 0.62 & 0.81 & \\
\hline & 1 & 1.41 & 1.28 & 1.57 & 0.84 & \\
\hline $\mathrm{SNV}+2^{\text {nd }}$ derivative & 2 & 1.08 & 0.94 & 1.13 & 0.65 & \\
\hline & 3 & 0.84 & 0.82 & 0.90 & 0.63 & \\
\hline & 4 & 0.78 & 0.75 & 0.79 & 0.61 & \\
\hline
\end{tabular}




\begin{tabular}{|c|c|c|c|c|c|c|}
\hline & & \multicolumn{4}{|c|}{ Spectral Range $\left(\mathrm{cm}^{-1}\right)$} & \\
\hline Data pretreatment $\downarrow$ & $\begin{array}{c}\text { Number } \\
\text { of PLS } \\
\text { Factors } \downarrow\end{array}$ & $11900-4100$ & 9000-4100 & $11900-5550$ & $7500-5000$ & \\
\hline \multirow{4}{*}{ None } & 1 & 6.51 & 8.93 & 6.67 & 3.82 & \\
\hline & 2 & 4.53 & 4.54 & 4.01 & 3.98 & \\
\hline & 3 & 3.92 & 3.90 & 3.92 & 3.26 & \\
\hline & 4 & 3.88 & 3.68 & 4.01 & 3.38 & \\
\hline \multirow{4}{*}{ SNV } & 1 & 9.05 & 9.05 & 7.93 & 7.85 & \\
\hline & 2 & 7.87 & 7.96 & 7.32 & 7.82 & \\
\hline & 3 & 7.88 & 8.21 & 6.96 & 6.50 & \\
\hline & 4 & 7.82 & 8.26 & 6.72 & 7.39 & \\
\hline \multirow{4}{*}{$1^{\text {st }}$ derivative } & 1 & 8.68 & 9.49 & 6.17 & 7.65 & 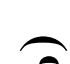 \\
\hline & 2 & 8.83 & 9.25 & 5.95 & 5.32 & $\underbrace{2}$ \\
\hline & 3 & 8.98 & 8.93 & 6.02 & 5.71 & \\
\hline & 4 & 8.96 & 8.47 & 5.97 & 5.78 & A \\
\hline \multirow{4}{*}{$2^{\text {nd }}$ derivative } & $\overline{1}$ & 6.44 & 6.16 & 6.53 & 3.00 & {$[-1$} \\
\hline & 2 & 6.56 & 6.13 & 6.57 & 3.37 & in \\
\hline & 3 & 6.43 & 6.26 & 6.68 & 3.54 & \\
\hline & 4 & 6.42 & 6.25 & 6.28 & 3.68 & $\boldsymbol{\alpha}$ \\
\hline \multirow{4}{*}{$\mathrm{SNV}+1^{\text {st }}$ derivative } & 1 & 7.74 & 7.98 & 6.19 & 4.82 & \\
\hline & 2 & 7.92 & 7.77 & 5.94 & 4.00 & \\
\hline & 3 & 8.10 & 7.53 & 5.95 & 4.45 & \\
\hline & 4 & 8.14 & 7.06 & 5.79 & 4.63 & \\
\hline \multirow{4}{*}{$\mathrm{SNV}+2^{\text {nd }}$ derivative } & 1 & 6.25 & 4.84 & 6.53 & 3.38 & \\
\hline & 2 & 6.26 & 4.31 & 6.54 & 3.63 & \\
\hline & 3 & 6.05 & 4.45 & 6.63 & 3.74 & \\
\hline & 4 & 5.94 & 4.46 & 6.21 & 3.73 & \\
\hline
\end{tabular}




\begin{tabular}{|c|c|c|c|c|c|c|}
\hline & \multicolumn{4}{|c|}{ Spectral Range $\left(\mathrm{cm}^{-1}\right)$} & \\
\hline Data pretreatment $\downarrow$ & $\begin{array}{c}\text { Number } \\
\text { of PLS } \\
\text { Factors } \downarrow\end{array}$ & $11900-4100$ & $9000-4100$ & $11900-5550$ & $7500-5000$ & \\
\hline \multirow{4}{*}{ None } & 1 & 18.9 & 21.2 & 18.3 & 22.0 & \\
\hline & 2 & 19.0 & 18.5 & 18.7 & 19.4 & \\
\hline & 3 & 18.8 & 14.8 & 18.1 & 3.1 & \\
\hline & 4 & 18.5 & 13.7 & 17.8 & 1.0 & \\
\hline \multirow{4}{*}{ SNV } & 1 & 1.21 & 1.05 & 3.55 & 2.78 & \\
\hline & 2 & 1.13 & 1.25 & 3.70 & 5.13 & \\
\hline & 3 & 1.14 & 1.49 & 3.81 & 5.43 & \\
\hline & 4 & 1.42 & 2.92 & 3.98 & 5.49 & \\
\hline \multirow{4}{*}{$1^{\text {st }}$ derivative } & 1 & 3.78 & 3.74 & 18.33 & 1.19 & $\overparen{\overbrace{}}$ \\
\hline & 2 & 3.41 & 2.02 & 18.65 & 0.93 & $\underbrace{2}$ \\
\hline & 3 & 3.12 & 1.57 & 18.13 & 0.96 & \\
\hline & 4 & 2.89 & 1.52 & 17.78 & 1.00 & A \\
\hline \multirow{4}{*}{$2^{\text {nd }}$ derivative } & 1 & 4.37 & 4.13 & 4.45 & 3.55 & {$[-2]$} \\
\hline & 2 & 4.39 & 4.10 & 4.55 & 3.32 & in \\
\hline & 3 & 4.55 & 4.19 & 4.87 & 3.15 & \\
\hline & 4 & 4.80 & 4.54 & 5.23 & 2.98 & $\mathcal{L}$ \\
\hline \multirow{4}{*}{$\mathrm{SNV}+1^{\text {st }}$ derivative } & 1 & 3.88 & 3.85 & 4.20 & 1.21 & \\
\hline & 2 & 3.58 & 2.26 & 4.29 & 1.03 & \\
\hline & 3 & 3.33 & 2.02 & 4.57 & 1.13 & \\
\hline & 4 & 3.18 & 2.08 & 4.62 & 1.34 & \\
\hline \multirow{4}{*}{$\mathrm{SNV}+2^{\text {nd }}$ derivative } & 1 & 4.33 & 4.10 & 4.42 & 1.65 & \\
\hline & 2 & 4.34 & 3.99 & 4.52 & 1.65 & \\
\hline & 3 & 4.48 & 4.02 & 4.83 & 1.71 & \\
\hline & 4 & 4.70 & 4.27 & 5.17 & 1.71 & \\
\hline
\end{tabular}




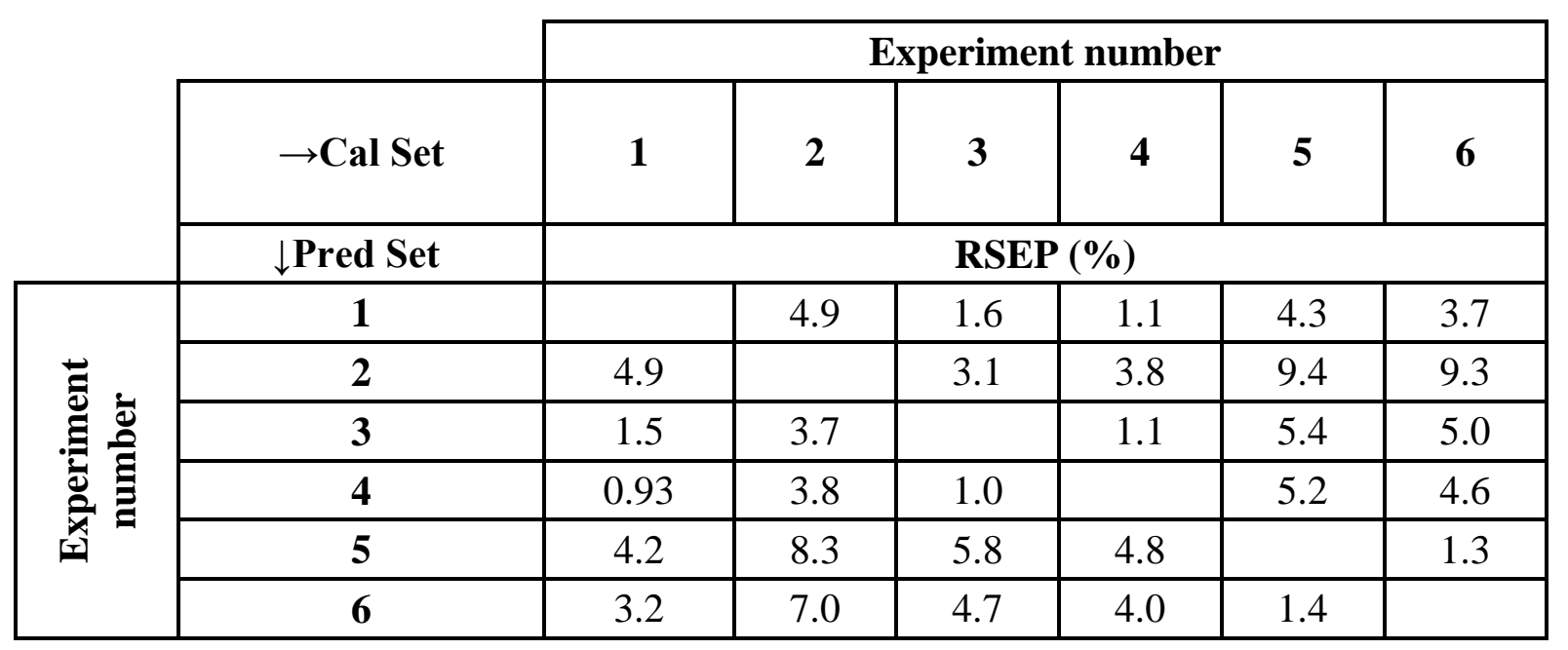




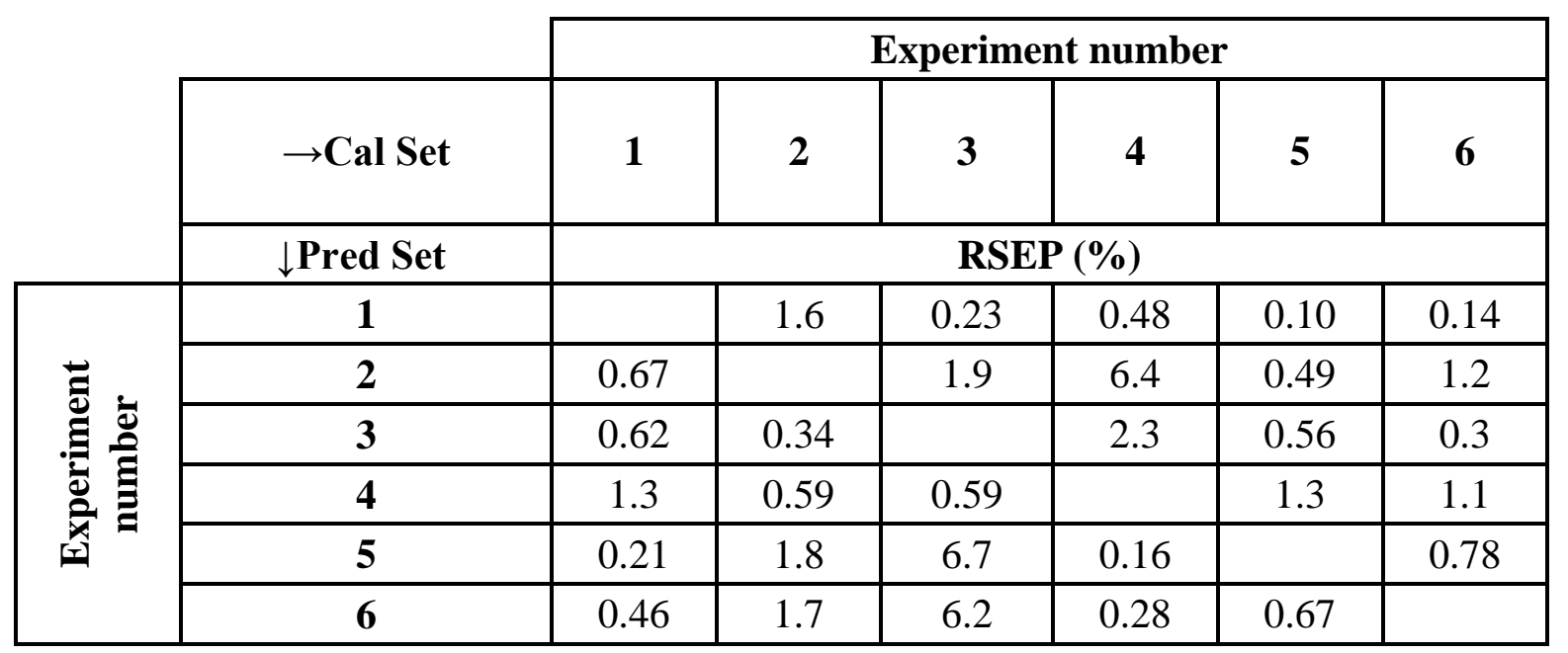


Step 1. Blend preparation
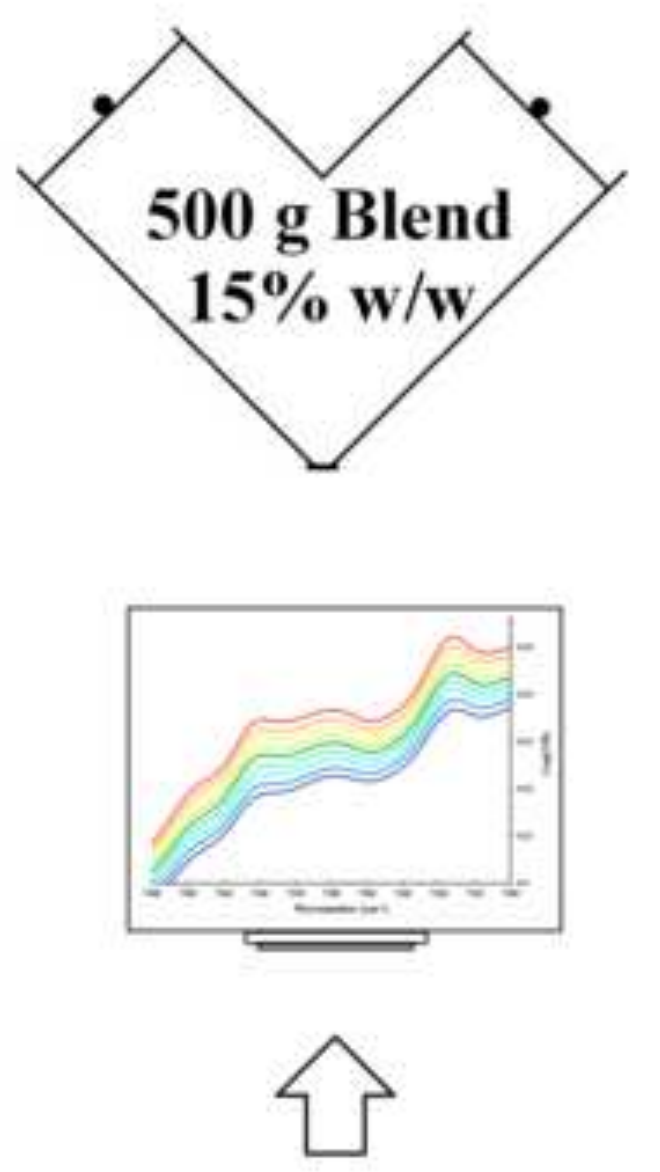

NIR

Step 5. Measurement
Step 2. Rotary sample divider
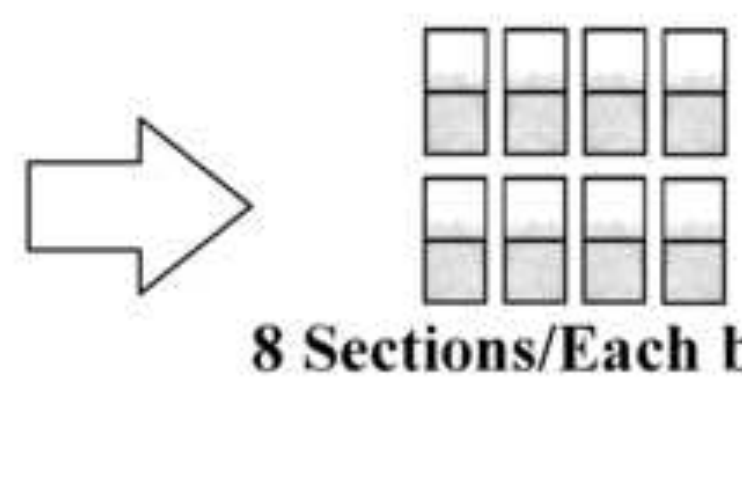

8 Sections/Each blend
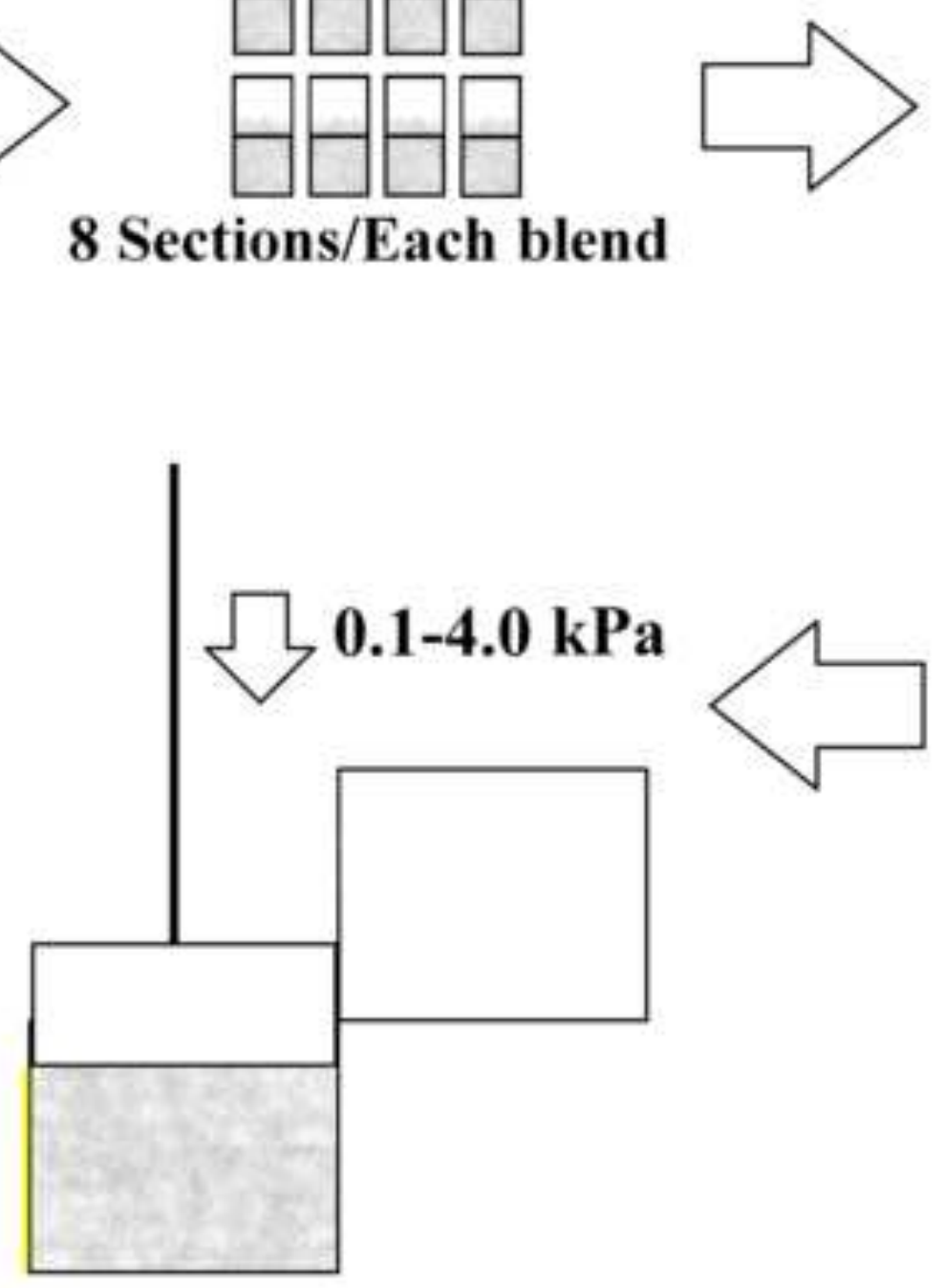

Step 3. Conditioning

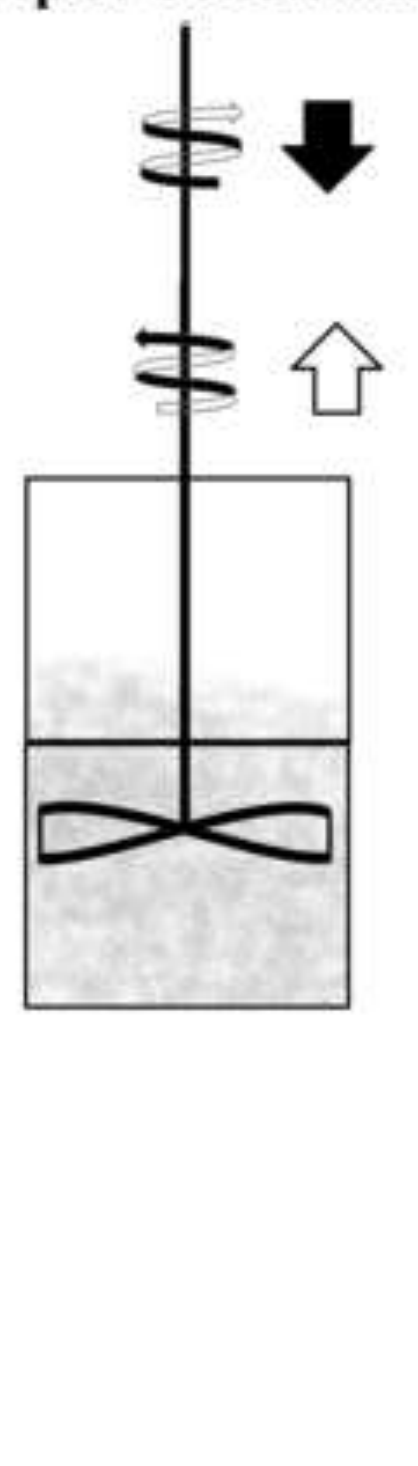

Step 4. Compression 

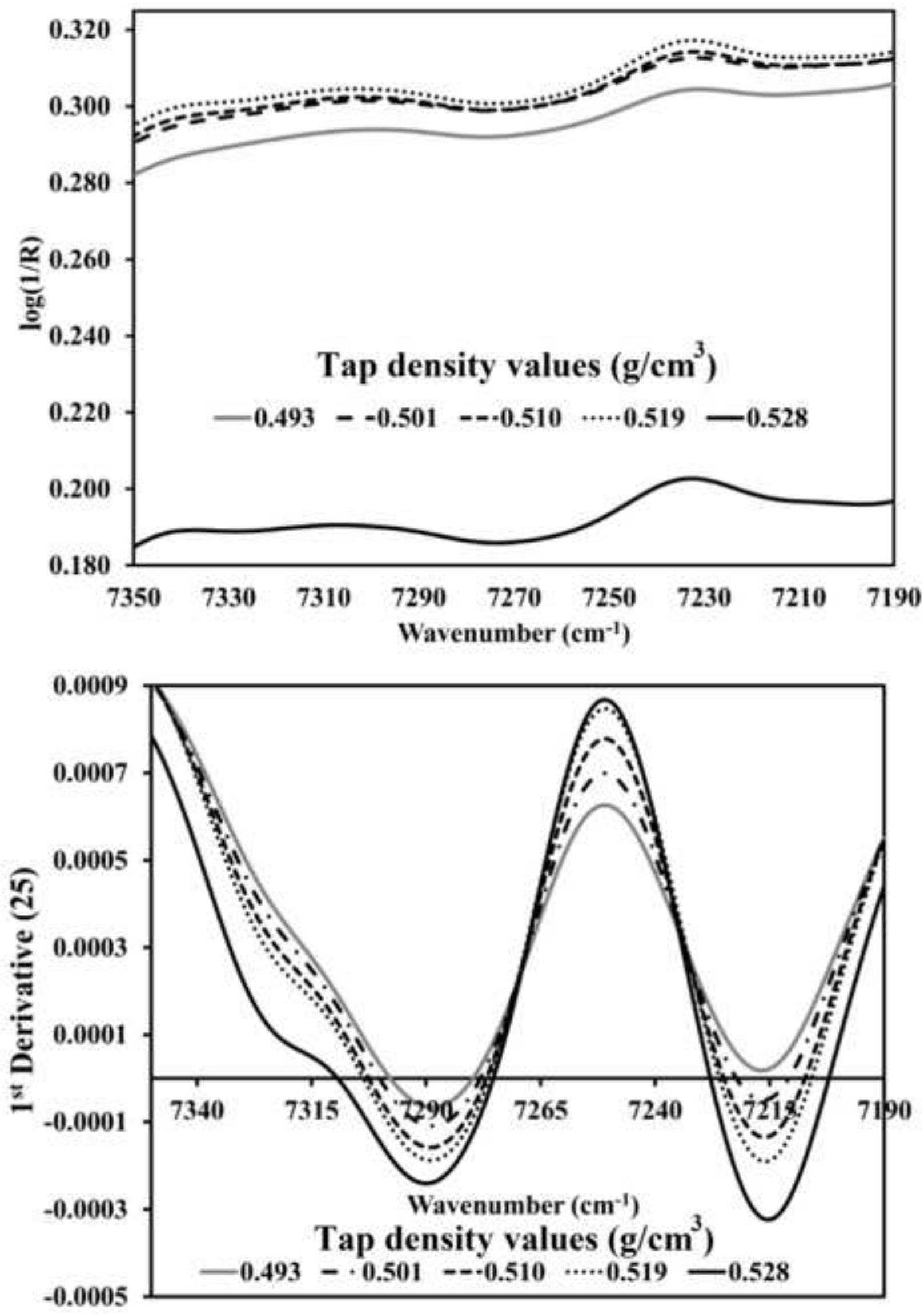
Fig. 3
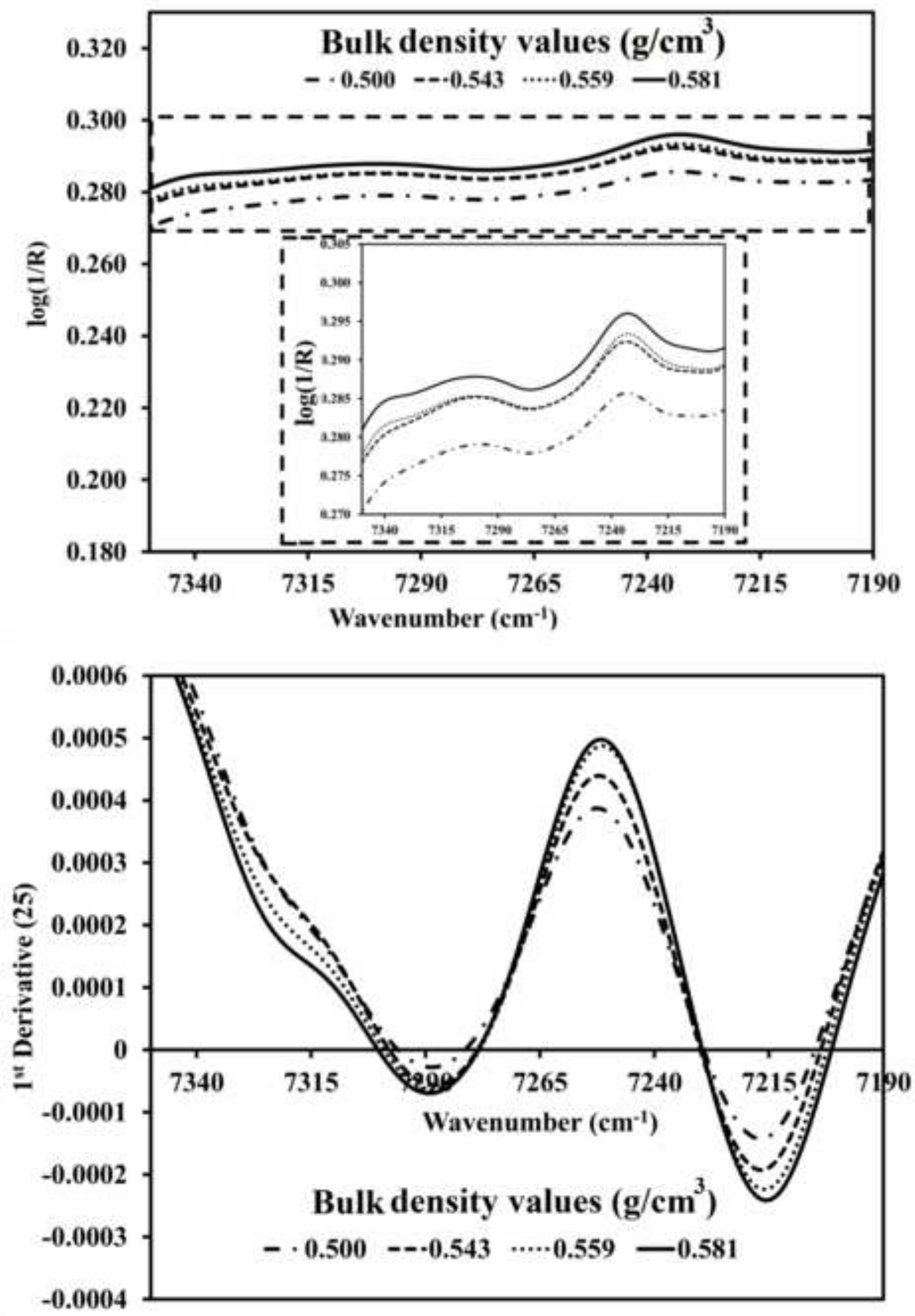
Fig. 4
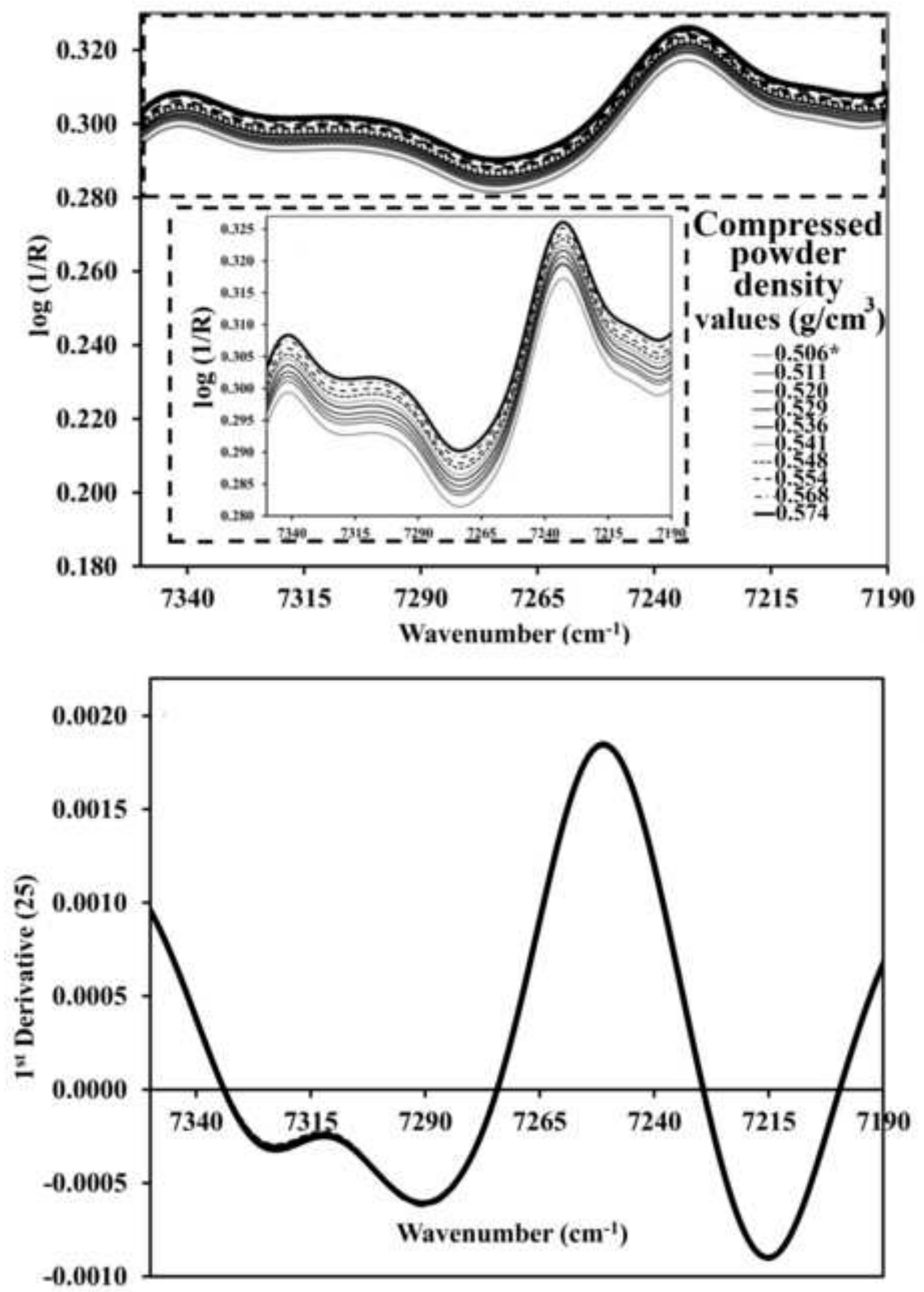

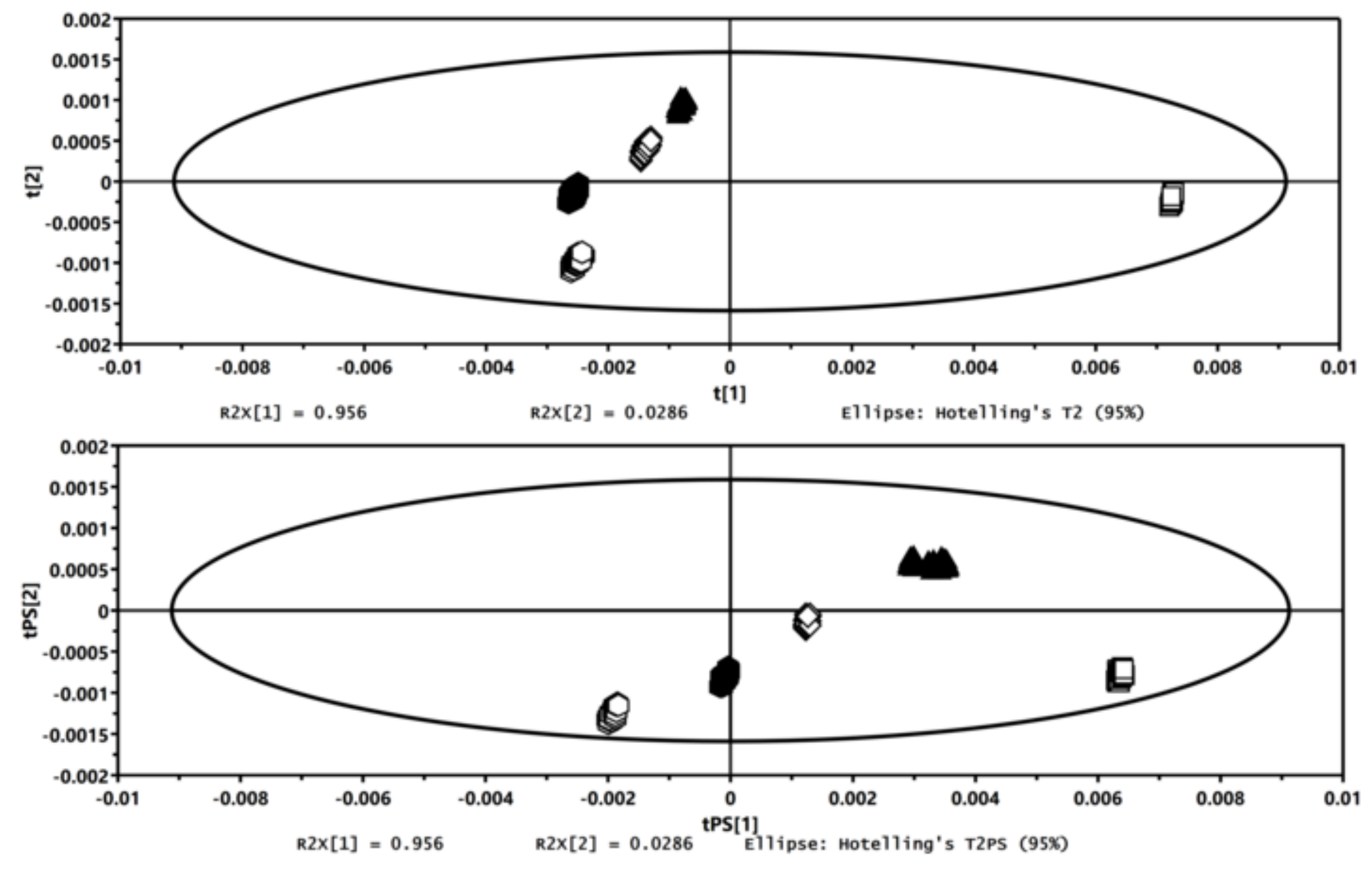


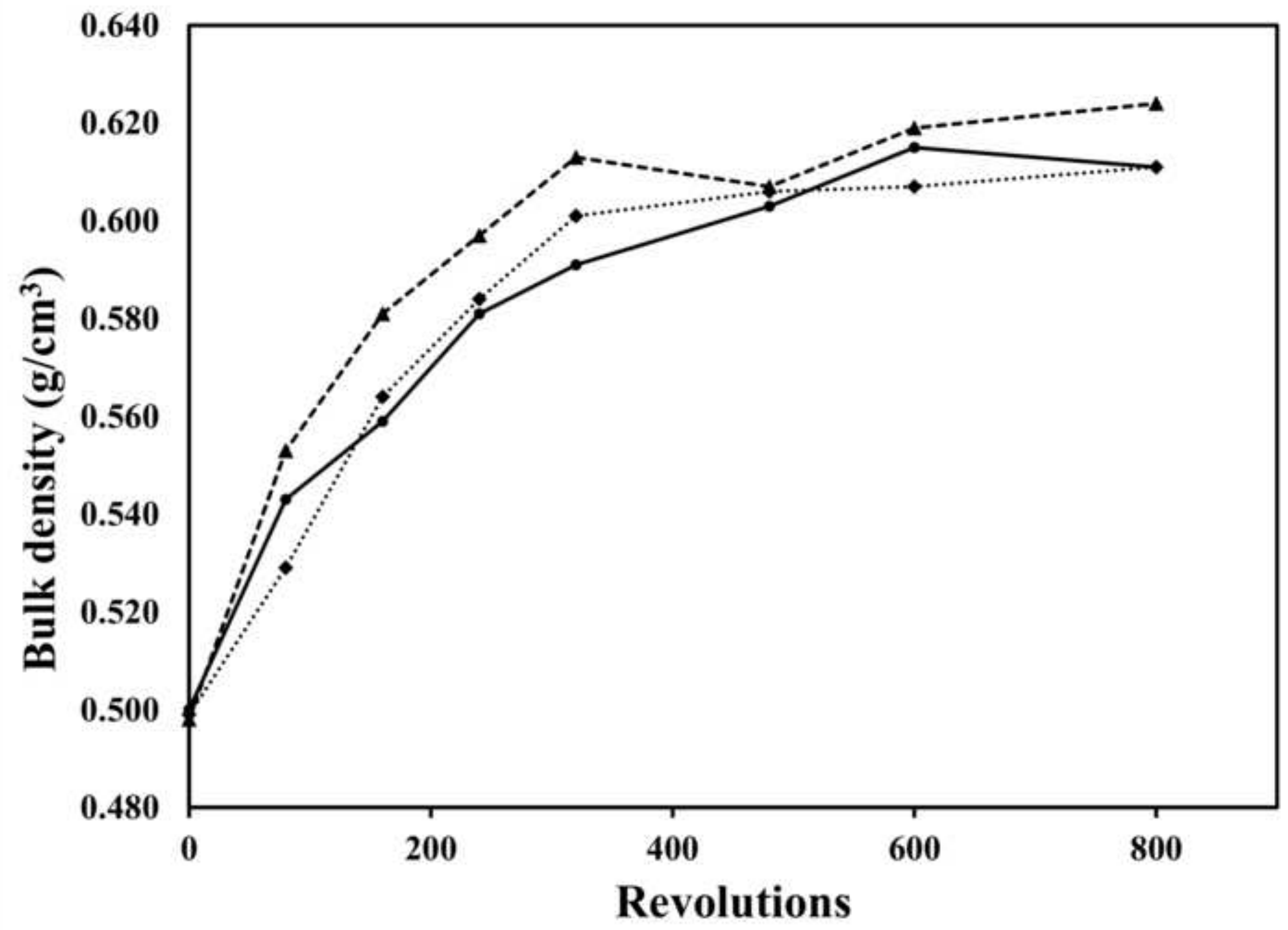



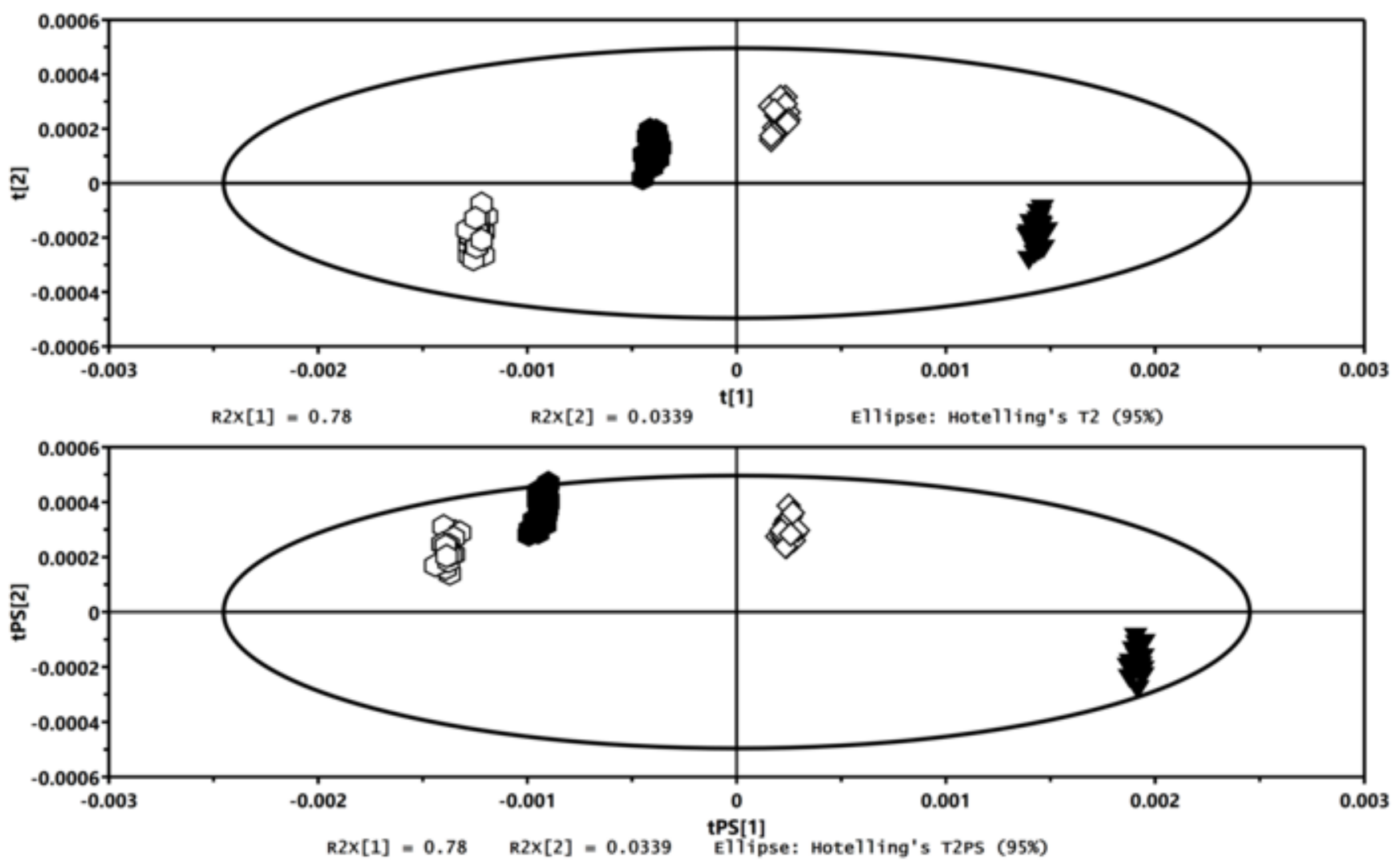
Fig. 8
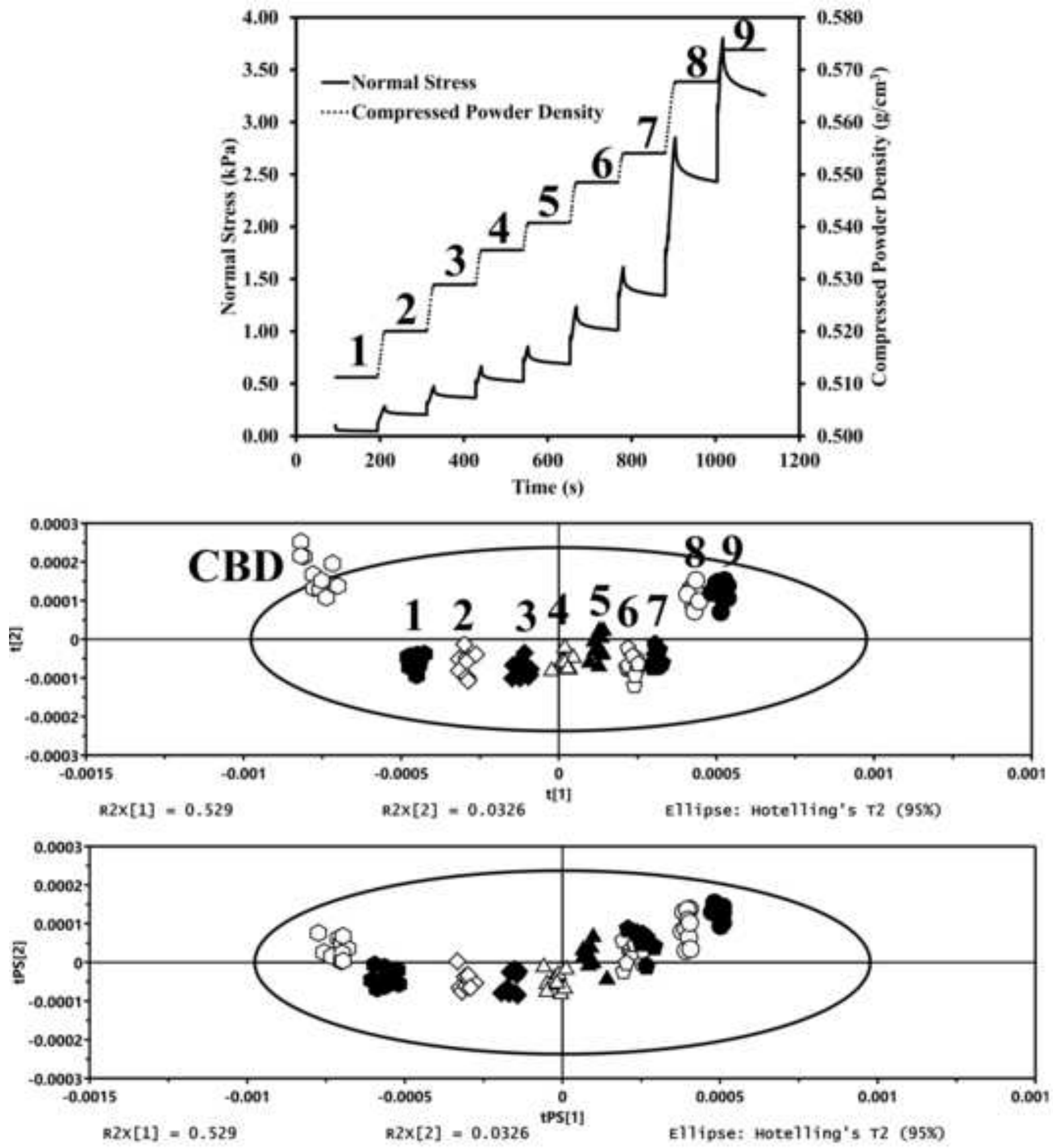


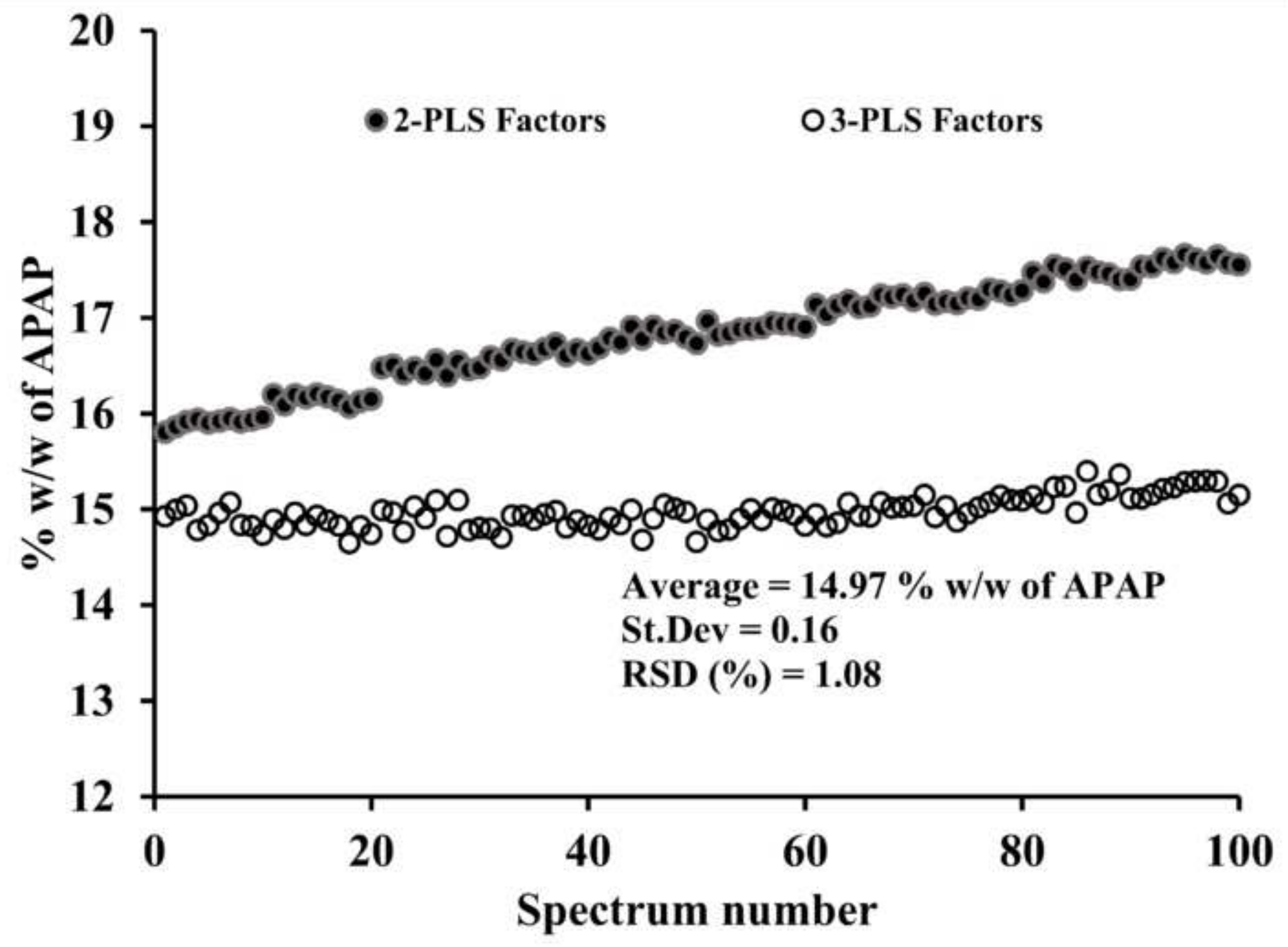



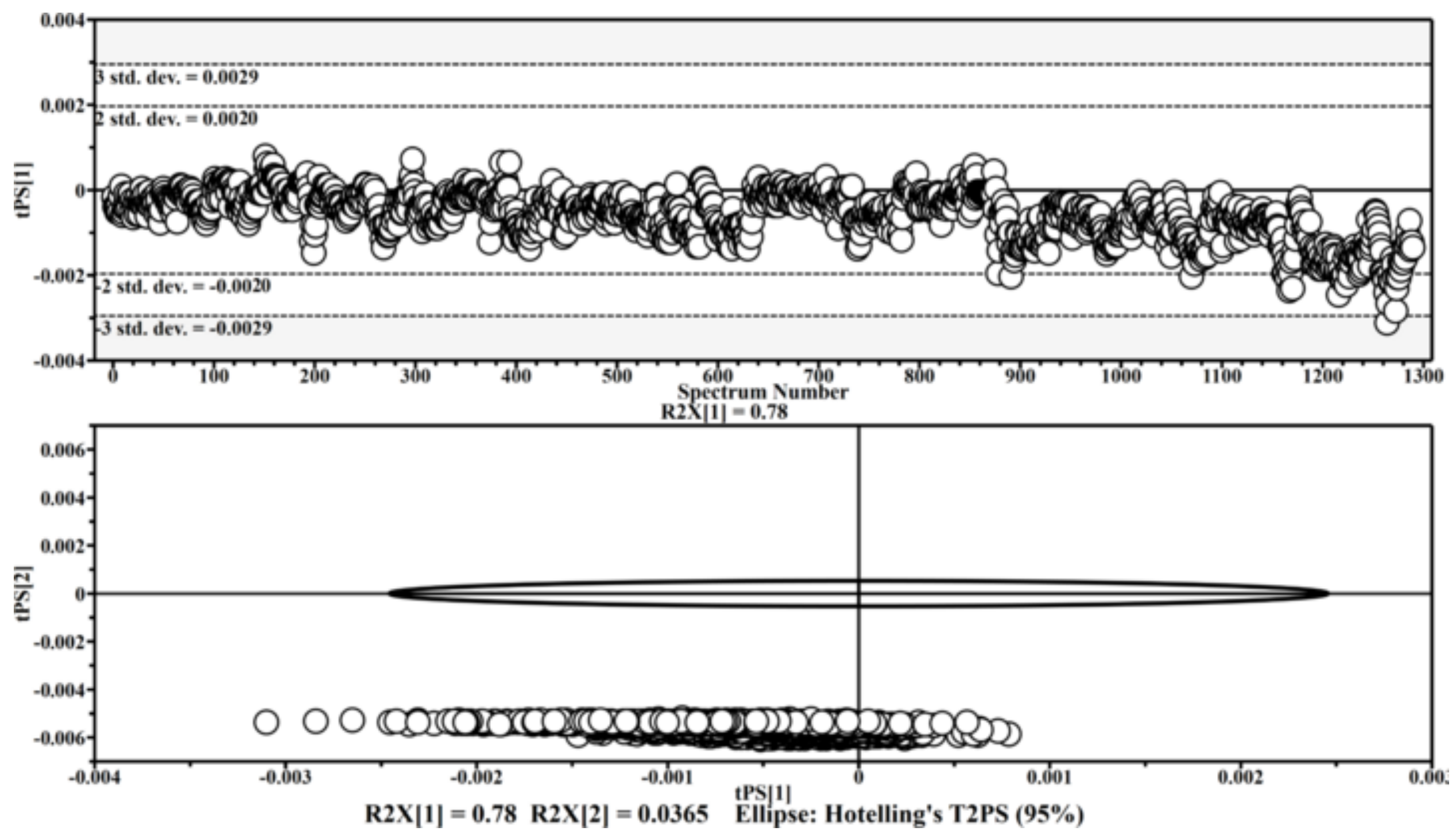


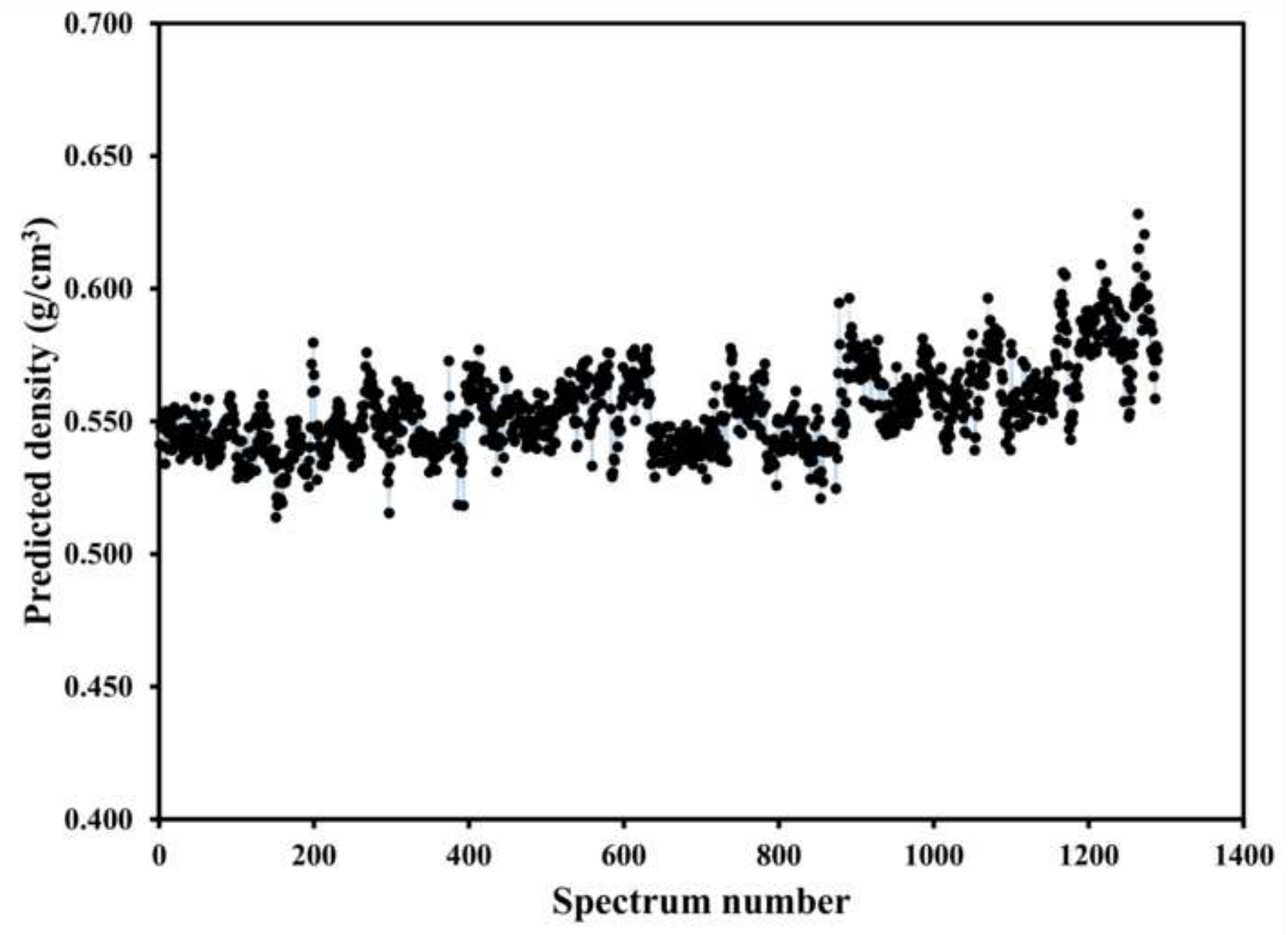




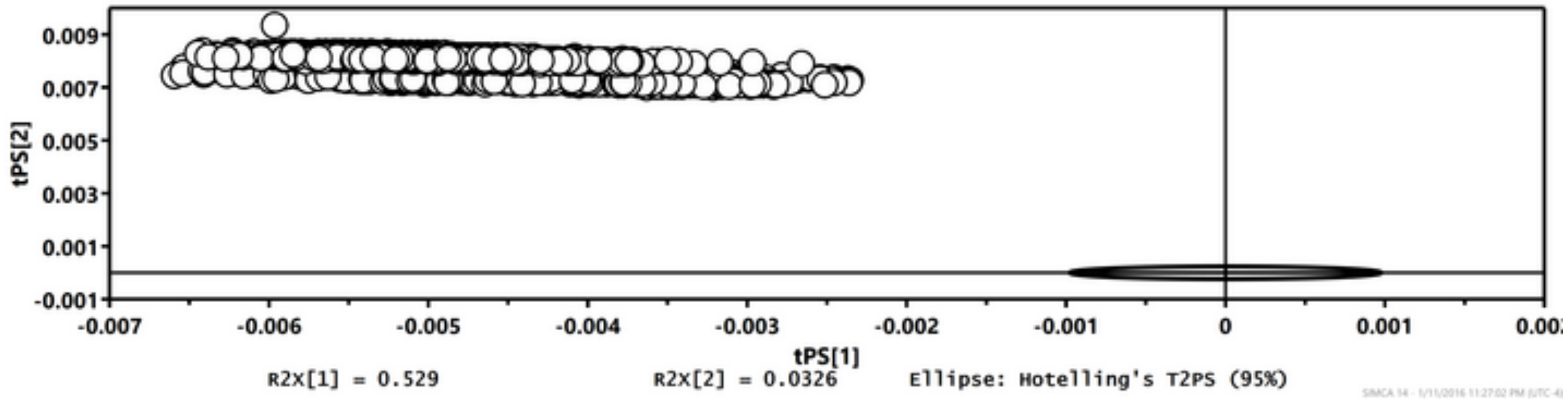




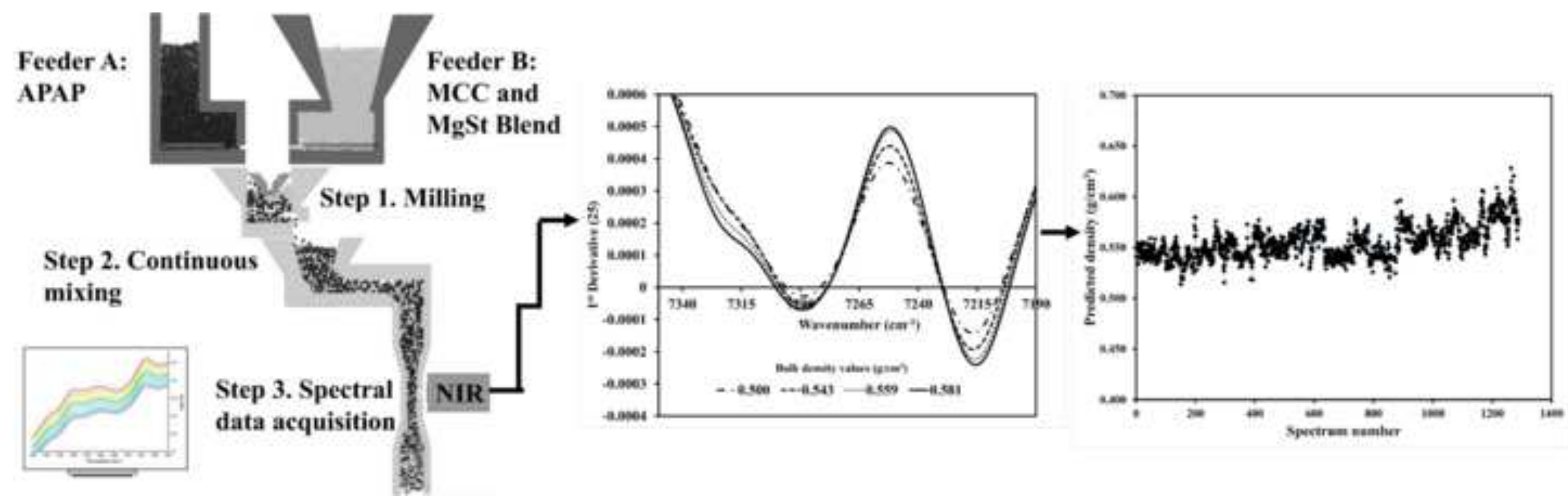

